\title{
Conflict, Chaos, and the Art of Institutional Design
}

\author{
Scott C. Ganz
}

November 9, 2021

\section{Abstract}

The metaphor of the organization as a garbage can is often invoked as a playful insult. However, as was recognized early on by management theorists studying garbage can ideas, the unpredictability arising from garbage can decision making has the potential to be adaptively rational for organizations facing complex task environments. The chaos produced by intraorganizational goal conflict and fluid participation in collective decision making can aid in search by enabling firms to escape local performance peaks or competency traps. The decades-old hypothesis that conflict and chaos could promote adaptively rational search, however, has largely been overlooked in research on organizational design. This paper uses an agent-based model to evaluate these competing views and, in the process, identify conditions under which garbage can decision making is indeed adaptively rational. In particular, I explore the conditions under which preference conflict and fluid participation in decision making promote effective search in an uncertain task environment. I show that the biased and chaotic outcomes that emerge as a result of garbage can decision making - the very features of garbage cans that lead them to be perceived to be dysfunctional - can facilitate short-term exploitation and long-term exploration of uncertain technical landscapes when organizations engage in serial judgment of local alternatives and internal conflict over desired outcomes is not too extreme. I conclude that decision making routines that encourage chaotic conflict are robust to bounded rationality and complex task uncertainty and thus should be included in the organizational designer's portfolio.

\section{Introduction}

The metaphor of the organization as a "garbage can" is often invoked as a playful insult. The description in Cohen et al. (1972) of "organized anarchies" - organizations characterized by unclear technology, problematic 
preferences, and fluid participation - is commonly used to explain why organizations make irrational and unreliable decisions. Accordingly, research in organizational design emphasizes how the symptoms of garbage can processes can be suppressed (Eisenhardt and Zbaracki, 1992, Padgett, 1980b) or exploited for individual gain (Pfeffer, 1981), but rarely when or why garbage can processes could be desirable.

However, as was recognized early on by management theorists studying garbage can ideas, the unpredictability arising from garbage can decision making has the potential to be adaptively rational for organizations facing complex task environments. The chaos produced by intraorganizational goal conflict and fluid participation in collective decision making can aid in search by enabling firms to escape local performance peaks or competency traps. Moch and Pondy (1977) thus propose that the garbage can may be "the organizational equivalent of an all-terrain vehicle" (360). Along these lines, Cohen (1984) identifies "search-enhancing conflict" as a possible remedy for boundedly-rational decision makers, concluding "the art of institutional design is, in part, to conceive of decision-making arrangements that will successfully harness the potential inherent in strongly held and partially divergent incentives" (446). Even more boldly, Pondy (1992) hypothesizes that garbage can decision-making routines explain why "the 66 oldest institutions in Western civilization consist of four parliaments and 62 universities" (260).

The decades-old hypothesis that conflict and chaos could promote adaptively rational search, however, has largely been overlooked in research on organizational design. In particular, the notion that decision makers with divergent preferences could produce better outcomes for a principal than decision makers with aligned preferences continues to be controversial. Perhaps the oldest theory in organizational design is the "ally principle," that is, "rational bosses prefer agents who are allies" (Bendor et al. 2001). When principals delegate to groups of agents with different preferences, agents can use their decision-making authority to bias outcomes toward their own goals and away from the principal's desired outcome Bendor and Meirowitz, 2004). Further, the outcomes of collective decision making can be unreliable and unpredictable when participants change over time or alternatives can be adopted without unanimous support, because choices made in one period can be overturned in the next by a new coalition unhappy with the new status quo (McKelvey, 1976). Additionally, conflicting preferences inside organizations constrain information acquisition (Ganz, 2018) and sharing (Crawford and Sobel, 1982), as well as fomenting ill will that stands in the way of effective coordination (Eisenhardt et al., 1997; Jehn, 1997). Scholars throughout the social sciences thus tend to regard goal disagreement as an unfortunate side effect of more productive cognitive conflict - diversity in ideas, knowledge, and experience - rather than a desirable feature of decision-making routines.

This paper uses an agent-based model to evaluate these competing views and, in the process, identify conditions under which garbage can decision making is indeed adaptively rational. In particular, I explore how preference conflict and fluid participation in decision making promote effective search in an uncertain 
task environment. The model envisions an executive who seeks to improve on an existing strategy. The executive chooses between two organizational designs: delegate to an ally who makes decisions dictatorially or delegate to a garbage can, a committee of three decision makers with partially divergent goals whose attendance at meetings is stochastic. Decision makers evaluate the desirability of strategies based on two criteria. The first criterion captures the objective quality of the outcome and is common interest. However, the mapping from strategies to quality is characterized by rugged uncertainty. The second criterion is contested within the organization and captures the political alignment of the outcome with each decision maker's goals.

In this way, the paper bridges canonical behavioral models of decision making from management theory and political economics. Formal models in both disciplines are concerned with decision making among agents who have imperfect mental representations of the mapping between strategies and outcomes. In management theory, this limited capacity is often driven by an imperfect understanding of the complex interconnections between strategic choices and search heuristics that prioritize small, incremental changes over larger, more uncertain ones (Puranam et al., 2015). In political economics, decision makers' limited capacity to predict how strategic changes will affect the existing balance between internally-contested goals promotes the creation of commonly-understood labels that map sets of choices to lower-dimensional spaces that define a landscape where internal conflict takes place (Enelow and Hinich, 1984). However, these behavioral models of organizational decision making are rarely integrated, despite both being "foundational pillars" of the behavioral theory of the firm (Gavetti et al. 2007, 526). Existing models of decision making treat firms as either groups with aligned preferences facing complex search tasks or groups with conflicting goals, not both.

I propose a method for integrating these two views in a manner consistent with existing ideas about garbage can decision making and, more broadly, the behavioral theory of the firm. I model the mapping from strategic decisions associated with sets of choices to the common-interest quality criterion using the well-known NK model (Levinthal, 1997). Following Enelow and Hinich (1984), I also map these collections of decisions to a two-dimensional political space in which decision makers evaluate proposed strategies based on the dissimilarity between the proposal and their most favored outcomes.

I define the mapping between strategies and a location in political space using a Hue-Saturation-Intensity (HSI) colorspace transformation (Gonzalez and Woods, 2018). Briefly, the political label assigned to each strategy is represented by the chromaticity of a color, where each component choice in the strategy is akin to a quantity of colored light projected onto a white wall. Chromaticity defines perception of the quality of colored light by the human eye and is commonly represented by a location in the unit disk. Hue is the angular coordinate and corresponds to the name of the color in the red-orange-yellow-green-blue-purple 
rainbow. Saturation is the radial coordinate and corresponds to the color's purity, where less pure colors appear more gray. Decision makers thus evaluate the desirability of a strategy in the political space in terms of the divergence between the projected color mixture associated with a strategy and the color defined by their most favored outcome.

The benefits of using a colorspace transformation are three-fold. First, it permits small changes to strategies to generate small deviations in the political space, on average. A small amount of blue light added to a screen saturated with pure red will turn the projected color slightly more purple. Second, colorspace representations of the dimensions of conflict - e.g., referring to policy agendas in terms of their location in a red-blue spectrum - are commonly-used heuristic devices (even if the algebraic mapping from collections of projected colored light to the two-dimensional chromaticity plane is not) (see, e.g., Ansolabehere et al., 2006 , Barnett and Woywode, 2004, Di Giuli and Kostovetsky, 2014). Finally, mapping strategies to locations in the unit disk - as opposed to a higher-dimensional space or the Cartesian plane - permits a tight correspondence between the structure of political bargaining in my model and the lengthy theoretical literature in political economics on multidimensional spatial bargaining (see, e.g., Austen-Smith and Banks, 1999, for a review).

I show that the biased and chaotic outcomes that emerge as a result of garbage can decision makingthe very features of garbage cans that make them perceived to be dysfunctional - can facilitate short-term exploitation and long-term exploration of uncertain technical landscapes when organizations engage in serial judgment of local alternatives (Levinthal, 1997, Padgett, 1980a). When executives delegate to allies and the mapping between strategies and outcomes is rugged, the organization is likely to become stuck on a local peak. When they instead delegate to garbage cans, the increased exploration leads to improved long-term performance, so long as there is not too much internal disagreement. In the short-term, delegating to garbage cans is also functional, because coalition-based decision making increases the selection threshold for adopting a new strategy. In the medium-term, however, delegating to an ally produces better outcomes, because the ally more efficiently ascends local performance peaks. I show that these results are robust to changes in the task environment, voting rules, committee sizes, mappings from strategies to the political space, and individual utility functions. I conclude that, just as individual errors in judgment are sometimes functional (Knudsen and Levinthal, 2007) and hierarchical decision making can balance search and stability (Rivkin and Siggelkow, 2003), decision-making routines that encourage chaotic conflict are robust to bounded rationality and complex task uncertainty and thus should be included in the organizational designer's portfolio. 


\section{Background}

\section{Garbage Cans and Organized Anarchies}

The concept of the organized anarchy introduced in Cohen et al. (1972) builds on three observations about universities. First, universities are "conflict systems in which different participants pursue different goals" (Cohen et al. 2012, 21) Second, decisions in universities are rife with causal ambiguity. It is hard to predict how changes to policies will impact key outcomes. Third, decision makers have limited energy and attention. As a result, not all decision makers participate in every choice and collective decisions depend on who shows up.

The original FORTRAN simulations describe a cacophonous organization where decision makers lack agency, choices are often made with no problems attached, and problems queue as choices become backlogged with unresolved problems. Yet, the legacy of Cohen et al. (1972) is more strongly tied to the organized anarchy concept than the particulars of the computational model (Cohen et al., 2012). In their essay reflecting upon decades of management research inspired by their original paper, Cohen et al. (2012) wistfully note that the garbage can model has come to be a self-assigned family name, rather than a symbol of genetic inheritance: "a large number of studies have made good use of the name 'garbage can,' rather in the same way that a number of iron craftsmen took the name 'Smith'" (26). Cohen et al. (2012) highlight three major streams of research in this family. The first used the Garbage Can Model as the basis for descriptive research on organizational decision making. The second examined how intelligent actors navigate, or even exploit, garbage can decision making. The third reintroduced order into organizations characterized by garbage can pathologies. The garbage can model, today, has become a broad spectrum of theories that vary considerably depending on how much rationality is introduced into an original framework that strips organizations and their members of all intention.

The lion's share of research on organizational design focuses on the second characteristic of organized anarchies: causal ambiguity (see Puranam et al., 2015, for a review). The inability of organizations to predict the outcomes of their choices means that successful organizations develop routines that are well-adapted for the complexity of their task environments. When environments are single-peaked, maximal performance is achieved by sequentially exploiting higher-performing alternatives. When environments are rugged, in contrast, a balance of exploration and exploitation produces better long-term performance. This assumption that organizations and their members are goal-oriented but boundedly rational is thus frequently added to agent-based models in the garbage can family (Lomi and Harrison, 2012).

The first and third characteristics, in contrast, are integral to canonical models of bargaining in political 
science (see, Austen-Smith and Banks, 1999, for a review), but receive less attention in recent research in the garbage can family (Bendor and Shotts, 2012, Levinthal, 2012). Numerous qualitative studies describe how organizational decision making requires resolving conflict among powerful internal coalitions with differing goals (see Mithani and O'Brien, 2021, for a recent review). Common sources of intraorganizational disagreement include how to distribute scarce resources, how to evaluate organizational performance, and how to pursue strategic goals. Prior studies also emphasize how shifts in power, intrafirm social networks, and limited decision maker attention produce variability in which interests are represented in collective decision making over time (Eisenhardt and Bourgeois, 1988, Fligstein, 1990, Pfeffer, 1981). For example, Eisenhardt and Bourgeois (1988) describe the internal conflict among executives at a microcomputer firm surrounding a potential name change:

All executives opposed the chairman's decision to change the name...with the VPs of finance and marketing being the most active in their opposition. However, they persisted in familiar behaviors - that is, both tried to coopt the president and to engage their respective coalition partners. However, the VP of sales, the coalition partner of the VP of marketing, was busy with sales channel problems, and the VP of manufacturing, the coalition partner of the VP of finance, simply decided that he was too busy to bother. (755)

The lack of attention paid to political conflict in theories of organizational decision making extends beyond the garbage can model (Ganz, 2018, Gavetti et al., 2012, Marengo, 2020). Research on intraorganizational conflict in management theory often assumes that organizations are teams with aligned goals. Instead of exploring how conflicting preferences impact performance, research focuses on the costs and benefits of interpersonal animosity (relationship conflict), different beliefs about how best to accomplish the task (task conflict), or disagreement about how to coordinate activities and assign roles (process conflict) (Behfar et al. 2011). Experimental studies examining relationship and process conflict demonstrate unambiguously negative effects on team performance (De Dreu and Weingart, 2003). Research examining the potential for task conflict to be performance enhancing has more mixed results. The notion that teams consisting of members that have diverse identities, beliefs, experiences, or expertise have the potential to arrive at better decisions than homogeneous ones is supported theoretically Battaglini, 2002, Csaszar and Eggers, 2013: Gilligan and Krehbiel, 1989) and empirically (De Dreu and Van de Vliert, eds, 1997). Heterogeneous groups take into account a broader information set (Gruenfeld, 1995), have access to a wider array of social resources (Reagans and Zuckerman, 2001), and consider alternatives more thoroughly (Jehn, 1995, Phillips et al. 2009). As a result, groups with diverse perspectives make better decisions (Phillips et al., 2009), particularly for non-routine tasks $(\mathrm{Jehn}, 1995)$ and in settings where social influence is pervasive Levine et 
al. 2014). However, experimental research on the impact of task conflict on team performance also identifies a number of boundary conditions, emphasizing that teams addressing complex problems that are also forced to manage intense task conflict - or, worse, task conflict that transforms into relationship or process conflictmay be unable to manage both the task and the conflict effectively, in the process offsetting the potential benefits associated with intragroup diversity (De Dreu and Weingart, 2003).

However, teams with aligned goals but different beliefs about how best to achieve a task differ in important ways from groups facing problematic preferences. When goals are aligned but beliefs differ, the organization faces a coordinated hill-climbing problem. If the team could effectively communicate and aggregate their private information, they would achieve the best expected outcome for all involved. An equilibrium of a game in which all participants have the same preferences is the outcome that maximizes utility for any participant. In contrast, when goals conflict, it becomes impossible to speak of a superordinate goal for the group. Instead of facing a common-interest game with heterogeneous beliefs, the group faces a political negotiation in which what is good for one member may be bad for another. This kind of affective conflict is at the heart of what Cohen et al. (1972) mean by problematic preferences (Cohen et al., 2012).

Prior research in political science emphasizes that the impact of problematic preferences on organizational decision making depends on who gets a vote and the routines that govern collective choice. If the same voters attend every meeting and decisions are made by consensus, then political conflict creates the problem of multiple equilibria or political gridlock. If any decision maker is happy with the current outcome, they have the power to stop all future exploration. When the set of voters change each period, political conflict creates the opposite problem, chaos. There is no guarantee that any stable outcomes exist, because those perceived as high quality for voters in one period may not be retained when the voters change. A rational executive facing a well-understood task environment, therefore, will never delegate to a group with conflicting preferences. In the case of rigid participation, bad outcomes are caused by inertial gridlock. In the case of fluid participation, they are caused by instability. A better choice is to delegate to an ally, that is, an agent with preferences aligned with the executive's.

I use Figure 1 to demonstrate the problems of gridlock and chaos in an example of decision making in an organization characterized by spatial preferences over outcomes. Spatial representations of preferences are common in bargaining models in political science (Austen-Smith and Banks, 1999), organizational economics (Gibbons et al. 2012), and more recently in organizational theory (Ganz, 2018). Spatial preferences summarize decision makers' relative ranking of outcomes through an analogy to Euclidean distance in an ideological space. The dimensions of the space represent key trade-offs about desired outcomes, e.g., market capitalization, sales growth, and product quality (Ethiraj and Levinthal, 2009) or people, planet, and profits (Elkington, 1994). Outcomes associated with potential alternatives are represented by points in the 
space. Each decision maker also has a bliss point in the space, which represents their most favored outcome. Decision makers prefer outcomes that are located nearer to their bliss point than those further away.

In the figure, four organization members $z_{0}, z_{1}, z_{2}$, and $z_{3}$ have bliss points that are indicated by their names. $z_{0}$ is an ally: its bliss point represents the executive's preferences. $x_{0}$ indicates the location of the status quo. $x_{1}, x_{2}$, and $x_{3}$ are alternative strategies currently on the agenda. The dashed lines represent the locations of potential alternatives that make the four decision makers indifferent from $x_{0}$. Thus, if the executive delegates the decision to its ally $z_{0}$, then $z_{0}$ selects among the alternatives favored to $x_{0}$, which in this case is just $x_{1}$.

Imagine instead that the executive delegates the decision whether or not to retain $x_{0}$ to $z_{1}$, $z_{2}$, and $z_{3}$, who collectively make decisions based on consensus. None of the alternatives on the agenda will be adopted. $x_{3}$ is not preferred to $x_{0}$ by any of the decision makers. $x_{1}$ and $x_{2}$ are preferred to $x_{0}$ by $z_{1}$ and $z_{2}$, but not by $z_{3} . x_{0}$ is thus Pareto optimal. In other words, the organization is stuck.

This problem of gridlock can be alleviated if participation in decisions is fluid, but in its place emerges the problem of unstable collective choices. Continue with the prior setup, but imagine only $z_{1}$ and $z_{2}$ show up to the meeting. $z_{3}$ does not get a vote. Assume the meeting considers alternatives on the agenda according to a random order and that once an alternative is adopted the meeting adjourns. If $x_{1}$ were adopted, then the executive would be quite happy. But, in the next period, assume that a new meeting is called to review the organization's strategy and only $z_{3}$ attends. $z_{3}$ could return the organization to $x_{0}$, but might also choose to implement alternative $x_{3}$. In the latter case, everyone is worse off than they were with the status quo. With more rounds and more alternatives added to the agenda, this process would continue ad infinitum with no guarantee that the adopted outcomes will ever make the executive better off than $x_{0}$. This is the problem of unstable collective choices (McKelvey, 1976).

\section{Chaos, Ruggedness, and Adaptive Rationality}

For an executive facing a rugged task environment, the chaotic outcomes arising from delegation to groups with problematic preferences and fluid participation are no longer necessarily a liability. Adaptively rational search strategies balance exploitation — speedy ascent of local peaks — and exploration — sufficient stochasticity to escape competency traps (Levinthal, 1997; March, 1991; O'Reilly and Tushman, 2013, Puranam et al. 2015). This paper uses a formal model to explore the possibility that garbage cans produce search routines that achieve this balance.

This paper thus relates to prior studies on how decision making institutions impact the search-andstability trade-off. Prior research at the intersection of organizational design and adaptive search primarily 
focuses on hierarchical decision making structures (Csaszar and Eggers, 2013; Padgett, 1980b; Rivkin and Siggelkow, 2003, Siggelkow and Levinthal, 2003). This work highlights the importance of allocating authority over decisions in a way that reflects task interdependencies (see Rivkin and Siggelkow, 2003, for a review). However, Siggelkow and Levinthal (2003) and Rivkin and Siggelkow (2003) also note the potential for decision-making routines that are partially misaligned with task interdependencies to aid exploration, leading to improved long-term performance when executives have the capacity to intervene once high-quality strategies are discovered.

Prior research on the impact of goal conflict on organizational performance similarly tends to find that teams with goals aligned with the organization's outperform teams with division-specific goals when tasks are interdependent (Rivkin and Siggelkow, 2003) and that organizations seeking to maximize performance on a single goal outperform those with many goals (Ethiraj and Levinthal, 2009). In their study of goal multiplicity and organizational search, Ethiraj and Levinthal (2009) find that organizations with many goals perform better when allocating distinct goals to different departments than when divisions attempt to maximize performance across many goal dimensions simultaneously (see also Shepsle and Weingast, 1981 for a similar conclusion in legislative contexts). Their study thus hints at the potential for goal conflict to be performance enhancing and therefore comes closest to what is being proposed here.

In order for chaotic conflict to be performance-enhancing, however, there still needs to be a mechanism through which stability is achieved once a high-performing strategy is identified. The chaotic search induced by sequential negotiation by a fluid set of decision makers has the potential to lead to valuable strategic exploration. But, too much exploration is as bad as too little. I propose that this stability is created by the unclear technology, itself. Decision makers with different political preferences may still have a common interest in high quality outcomes. If the task environment is rugged, the inability of boundedly-rational decision makers to predict the quality of outcomes associated with new strategies can lead groups with divergent political preferences and fluid participation in decision making to still reach a durable consensus. For example, all decision makers in a university might prefer a more successful football team to a less successful one, but their individual evaluations of their school's football program may also reflect concerns about "the essence of a liberal education, the relations of the school to ethnic minorities, or the philosophy of talent" (March and Olsen, 1976, p. 175). Because coaching changes have an unpredictable impact on future team performance, the partial alignment of the decision makers' preferences through the common desire for more wins means that a football coach who wins enough games each year will keep their job, notwithstanding concerns about the poor academic performance of their players or the racial composition of the coaching staff.

Existing models in the garbage can family - and in management theory more broadly - fail to address the 
dynamics of search when decision makers face a problem evaluated according to both a complex, commoninterest criterion - e.g., how to win football games - and a politically-contested criterion - e.g., the panoply of other concerns surrounding the athletic program. Yet, a growing literature in management demonstrates that many strategic decisions are both technically complex and foment intraorganizational political conflict. For example, Kellogg (2009) describes how hospital administrators seeking to reduce the number of hours worked by exhausted residents had to both carefully redesign intraorganizational routines to avoid "dropped balls" and overcome overt internal conflict between "defenders" and "reformers." Zbaracki and Bergen (2010) similarly document how a large capital investment made by a manufacturing firm that reduced per-unit costs inflamed political conflict between the marketing and sales teams surrounding pricing strategy. Finally, Kaplan (2008) emphasizes how different teams in a communications technology firm reached divergent conclusions about the desirability of potential investments in optics technology due to oppositional cognitive frames. The model proposed here departs from prior work by permitting strategic search to be both a source of technical uncertainty and a site of internal contestation, while, in the process, bringing together these oft-siloed pillars of the behavioral theory of the firm.

\section{Model}

The model features an organization searching a landscape by adopting local changes to a strategy. The desirability of a strategy to individual decision makers is a function of its quality and the location of the strategy in a political space. The quality of the strategy is common interest. All else being equal, all decision makers prefer higher quality strategies to lower quality ones. But, strategic changes are also politically contested. Decision makers have different goals that lead to conflicting views about which strategies to adopt.

The organization consists of four decision makers: an ally to the executive $z_{0}$ and three decision makers $z_{1}, z_{2}$, and $z_{3}$. The ally has preferences that perfectly align with the executive's. The other decision makers have preferences that differ from the executive's and from each other's. At the outset, the executive determines whether decision making will be made dictatorially or by committee. In the former case, $z_{0}$ alone evaluates alternatives. In the latter case, $z_{1}, z_{2}$, and $z_{3}$ evaluate alternatives. They make decisions based on consensus. Participation in committee meetings may be fluid, which means that decision makers sometimes miss meetings. When participation is fluid, attendance at meetings ranges from zero participants - in which case the status quo is maintained - to three - in which case $z_{1}, z_{2}$, and $z_{3}$ must all deem an alternative more desirable than the status quo in order for it to be adopted.

Strategies are characterized by a set of decisions corresponding to $N$ binary choices that are represented 
by a $N$-length bit string. Strategies map to both a common-interest quality value and to a location in the unit disk. The mapping from strategies to quality is characterized by rugged uncertainty. $z_{0}$ has a bliss point at the origin of the disk. $z_{1}, z_{2}$, and $z_{3}$ have bliss points that are equidistant from the origin and equally spaced from each other's. In each period, the organization chooses whether to retain the status quo or replace it with a local alternative, that is, an element in the set of one-bit changes to the current strategy.

The model thus integrates assumptions from organizational theory about search on uncertain technical landscapes with those from political science on spatial bargaining among actors with diverse preferences. In order to accomplish this, I use a colorspace transformation to map the bit string that determines the technical quality of a strategy into the Euclidean space where political conflict takes place. Next, I explore the assumptions of the model in greater detail, focusing in particular on aspects of the model that depart from prior work.

\section{Evaluating the Quality of Strategies}

The common-interest quality of strategies is determined by an NK landscape in an identical manner as in Levinthal (1997), which I summarize here briefly. Strategies are represented by a $N$-length bit string, denoted $\mathbf{x}$, where each bit represents a choice faced by the organization. The parameter $K$ represents the extent to which the contributions of each decision to common-interest quality depend on the decisions associated with other choices. If $K=0$, then the quality contribution of each component decision is independently determined. If $K=N-1$, in contrast, the quality contribution of every decision depends on the decisions associated with every other choice.

The strategy's quality $v(\mathbf{x})$ is calculated in the following way: Choices $x_{i}$ are arranged in a ring, where $i \in\{1, \ldots, N\}$ indexes choices. Decisions about each of the $N$ choices impact the quality of a strategy, but their individual contributions depend on the decisions associated with the $K$ other choices that follow in the bit string. Each $K+1$-bit interaction can therefore take $2^{K+1}$ potential values, depending on the decision regarding the focal choice and those for the $K$ choices that follow. The quality of each interaction $v\left(x_{i}\right)$ is represented by a random draw from the unit interval. The overall quality value of a strategy is the average quality contribution across the $N$ decisions, $v(\mathbf{x})=\sum_{i} v\left(x_{i}\right) / N$. In this way, the NK landscape creates a tunably rugged virtual world in which organizations search among alternative strategies, where $K$ captures the extent of the ruggedness.

Figure 2 illustrates how to derive the quality of a strategy from its bit-string representation in an NK landscape in which $N=6$ and $K=1$. The example begins with the strategy $\mathbf{x}=101001$. The six circles in the top-left represent the six choices $x_{i}$, where $i \in\{1,2,3,4,5,6\}$. The decisions associated with choices 
are indicated by whether the circles are empty (i.e., $x_{i}=0$ ) or filled (i.e, $x_{i}=1$ ). $v\left(x_{i}\right)$ represents the quality contribution associated with decision $x_{i}$. Because $K=1$, the quality contribution of each decision depends on the decision associated with the next choice in the ring, represented by the arrows in the top-left diagram. Thus, the quality contribution of $x_{1}$ depends on the realization of $x_{2}, x_{2}$ depends on $x_{3}$, and so on. Because $K=1$, there are four possible values $v\left(x_{i}\right)$ can take. In this example, if the focal decision $x_{i}$ and the subsequent decision $x_{i+1}$ are both 0 , then $v\left(x_{i}\right)$ is 0 . If $x_{i}$ is 0 and $x_{i+1}$ is $1, v\left(x_{i}\right)$ is $\frac{3}{4}$. If $x_{i}$ is 1 and $x_{i+1}$ is $0, v\left(x_{i}\right)$ is $\frac{1}{4}$. And, if both $x_{i}$ and $x_{i+1}$ are $1, v\left(x_{i}\right)$ is 1 . The overall quality of $\mathbf{x}$ is the average of the quality contributions across all $x_{i}$, which is $\frac{1}{2}$ for $\mathbf{x}=101001$.

Moving from the top-left to the bottom-right illustrates how the quality of $\mathbf{x}$ changes if $x_{3}$ is switched from 1 to 0 . The new strategy $\mathbf{x}^{\prime}=100001$. As a result of the change to $x_{3}$, the quality contributions of $x_{2}$ and $x_{3}$ change from $\frac{3}{4}$ and $\frac{1}{4}$, respectively, to 0 . Therefore, $v\left(\mathbf{x}^{\prime}\right)=\frac{1}{3}$.

Next, I explore how overall quality changes as a result of random incremental search. I simulate $2500 \mathrm{NK}$ landscapes and permit 20 periods of exploration following a strategy initialized at random. Figure 3 displays the distributions of changes in quality as a result of a one-bit change to strategy for $N=12$, where $K=0$ or $K=5$. Both histograms are symmetric and centered at zero with standard deviations of 0.034 and 0.084 , respectively. Incremental exploration is more likely to produce non-local effects on quality when the choices are coupled than when they are uncoupled. In Figure 4, I also present variograms that display the strength of the correlation between quality values conditional on the number of periods separating each observation. The horizontal axes represents how many periods elapse between observations. The vertical axes measure the semi-variance, which is half the mean-squared difference between the quality values. A steeply-sloped variogram indicates that knowing the quality of the current strategy is not especially informative about the quality of nearby strategies. In contrast, less steeply-sloped variograms imply that knowledge of the quality of the current strategy is informative about the quality of nearby alternatives. When $K=0$, the semi-variance is lower than when $K=5$. However, for $K=5$, the informativeness of the quality of current strategies on the quality of future strategies degrades more quickly than when $K=0$. For $K=5$, knowledge of the quality of a focal strategy provides little additional information about strategies more than 5 local transformations away. In contrast, for $K=0$, the mapping from the current strategy to its quality value provides additional information about the quality associated with strategies more than 10 local transformations away.

\section{Mapping Strategies into Political Space}

In addition to being evaluated according to a common-interest quality criterion, strategies map to a political space which captures conflict over desired outcomes. 
The intuition behind the mapping is that the 0 s and $1 \mathrm{~s}$ in the bit string also define a location on a red, green, blue (RGB) color wheel. The favorite color of $z_{0}$ is neutral, which lies at the center of the wheel. The other decision makers have different favorite colors. Strategies that map to colors that are more similar to the favorite color of a decision maker are more desirable than those that are more dissimilar.

Using the psychology of color perception as an analogy for modeling political conflict over strategic goals is an important innovation in this paper, but is also one that introduces several behavioral assumptions that are worth highlighting. Spatial representations of intragroup conflict involve three key simplifications (Enelow and Hinich, 1984). The first is that there exist commonly-understood dimensions that define the underlying space where conflict takes place. For example, Kaplan (2008) describes how managers' preferences at the communications technology firm were well-characterized in terms of multiple "poles on the spectrum", including conflict over whether optics would or would not be the future of telecommunications and over whether the firm should retain its traditional "lab mindset" or focus on meeting market demand. Proposed strategies are associated with labels that define locations in this politically-contested space. For example, the "last mile project"- a proposal to install high bandwidth connections at network access points - was associated with a pro-optical/pro-market location. These labels, however, do more than merely describe decisions regarding current sets of choices. They also create defaults for how future decisions will be made. Thus, adopting the "last mile project" is also symbolic of a change to the firm's strategy that is consistent with existing strengths in optics but is inconsistent with the lab-based culture of the firm that had previously prevailed.

Second, the location of a strategy in the political space is a function of the set of individual strategic choices. For example, in the conflict between the marketing and sales teams in the manufacturing firm described in Zbaracki and Bergen (2010), the decision to cut list prices is consistent with an increased emphasis on the marketing team in setting the firm's strategic direction. In contrast, creating opportunities for the sales team to offer discretionary discounts to favored clients is consistent with an increased emphasis on the sales team. The final decision by executives to slash list prices for newer products, on the one hand, but increase prices for older products, on the other, maps to a balance between the two poles. The precise functional mapping from sets of individual decisions to the location of a strategy in political space is context-dependent, but existing models in political economics assume that smaller changes to strategies produce smaller changes to political outcomes than larger changes do. Callander (2008) defines this property as partial invertibility and proportional invertibility. Partial invertibility requires that the knowledge of the location of one strategy in the political space provides some information about the political location of a local alternative to that strategy. Proportional invertibility requires that the informativeness of one strategy about the political location of an alternative is increasing in the similarity between the two strategies. 
Third, the desirability of a strategy for a decision maker is defined in terms of the divergence between their most favored outcome - i.e., their bliss point in the political space - and the location of the strategy. The dynamics of internal conflict, therefore, involve decision makers seeking to retain strategies that are closer to their bliss points and to replace strategies more distant from their bliss points with better aligned alternatives. Conflict emerges as a result of the trade-offs created when alternative strategies are adopted that change the existing political balance. In Kellogg (2009), for example, the creation of night floatsgroups of more senior residents in charge of managing overnight responsibilities so that interns could reduce their 120-hour per week workload - was aligned with the bliss points of reformers (directors, non-surgical and non-iron man residents, and interns) but opposed to the bliss points of defenders (staff surgeons and iron man chiefs and senior residents).

The colorspace transformation that I use to map individual strategic choices to locations in political space is consistent with these three assumptions. Each choice is associated with a specific quantity of projected colored light that is added to the mixture when the binary decision flips from 0 to 1 and is subtracted from the mixture when the binary decision flips from 1 to 0 . In this way, the colorspace transformation creates a functional mapping from sets of choices to locations in the political space that satisfies partial and proportional invertibility. On average, small changes to strategies involve a smaller change to the chromaticity of the projected mixture than larger changes do. Finally, the colorspace transformation offers a concept of distance that is easily quantified by the Euclidean distance between points in the unit disk, where the Euclidean locations of strategies and bliss points is defined by the locations of colors in a twodimensional chromaticity plane. Of course, there are many other potential transformations that would be consistent with these properties as well. What makes the colorspace transformation stand apart is that the conception of a colorspace as defining the dimensions of political conflict and the use of colors as labels for sets of decisions conforms to widely-held heuristics about the latent structure of political conflict. Further, although the mathematics of the colorspace mapping are somewhat complex, the intuition that some colors are more similar than other colors is intuitive enough for a toddler to understand.

Next, I describe how the colorspace transformation works in greater detail. I first randomly reorder the choices in the strategy in order to break potential correlations between the dependence structure induced by the NK model and the dependence structure assumed by the colorspace transformation. Then, I divide the choices in the reordered bit string into three separate components: $R, G$, and $B . R$ is defined by decisions 1 to $N / 3, G$ from $N / 3+1$ to $2 N / 3$, and $B$ from $2 N / 3+1$ to $N$. Each component is converted to its integer equivalent and scaled to be between 0 and 1 . Then, I map the three component values into a unit disk using the HSI colorspace conversion defined in Gonzalez and Woods (2018), where the location of each strategy $g(\mathbf{x})$ is defined by the hue and saturation of the color. Of note, the mapping from $\mathbf{x}$ to $g(\mathbf{x})$ is many-to-one. 
For example, any strategy with equal contributions of the three components maps to the origin, which is the executive's bliss point. For $N=6, \mathbf{x}=101010$ and $\mathbf{x}^{\prime}=010101$, for example, both map to the origin, i.e., $g(\mathbf{x})=g\left(\mathbf{x}^{\prime}\right)=(0,0)$.

Figure 5illustrates how the colorspace transformation works. I begin with $\mathbf{x}=101001$. (For simplicity, I assume that the random permutation of choices in the bit string returns the exact same order. That is, $x_{1}$ is first, $x_{2}$ is second, and so forth.) The binary representation of $R$ is 10 which has an integer equivalent of 2 . The maximum integer associated with a two-bit string is 3 . Therefore, $R$ evaluates to $\frac{2}{3}$. $G$ is also 10 , which evaluates to $\frac{2}{3}$. $B$ is 01 , which is equivalent to the integer 1 and thus evaluates to $\frac{1}{3}$. The hue associated with $\frac{2}{3}$ red, $\frac{2}{3}$ green, and $\frac{1}{3}$ blue lies halfway between red $\left(0^{\circ}\right)$ and green $\left(120^{\circ}\right)$. This is the angular coordinate of the strategy. Saturation, defined as 1 minus the ratio of the minimum color value and the average color value, is $\frac{2}{5}$. This defines the radial coordinate of the strategy 1 The polar coordinates defined by $R=\frac{2}{3}$, $G=\frac{2}{3}$, and $B=\frac{1}{3}$ blue are thus $\left(\frac{2}{5}, 60^{\circ}\right)$. I then convert the polar coordinates to Euclidean coordinates and calculate that $g(\mathbf{x})=(0.2,0.35)$.

The figure also demonstrates how a one-bit change in strategy can generate a distant move in ideological space. Moving from $\mathbf{x}$ to $\mathbf{x}^{\prime}$ represents a flip of the third decision from 1 to 0 . Now, $R=\frac{2}{3}$, $G=0$, and $B=\frac{1}{3}$. As a result of the reduction of the $G$ component, the new hue falls on the arc between red and blue. Saturation increases from $\frac{1}{2}$ to $1 . g\left(\mathbf{x}^{\prime}\right)=(0.87,-0.5)$. Taken together, the one-bit change in strategy generates an ideological shift that is greater than one unit.

Figure 6 illustrates all of the 64 possible strategies for $N=6$ mapped onto the unit disk. It also highlights local alternatives when $\mathbf{x}=101001$. The figure shows that local search produces alternatives that tend to be in the same ideological region as the status quo. That said, not all of the alternatives are immediate spatial neighbors. While the distance between 101001 and 111001 is quite small, larger jumps across the origin (101011) and to the periphery (101000) are also possible.

I next explore how random incremental search impacts changes to the location of strategies in the political space and on the distance of that location from the origin, using the same simulated data referenced before. Figure 7 shows the distributions of the change in political location and of the change in distance from the origin conditional on a random incremental change to a strategy. The former has a strong right skew, indicating that incremental changes to strategy indeed tend to have small effects on political location, although some changes have a non-local impact. The average change in political location resulting from a one-bit change to strategy is 0.31 and one standard deviation is 0.26 . The change in distance from the origin is symmetric and centered at zero with a standard deviation of 0.24 . Of note, the distribution is

\footnotetext{
${ }^{1}$ I assume that if the average color value is zero, the color maps to the origin. Alternative formulations in which the absence of color maps to the periphery produce nearly identical results.
} 
fat-tailed, which is an oft-observed empirical signature of the serial decision-making process proposed in Padgett (1980a). In Figure 8, I also present variograms measuring the intertemporal correlation of the strategy's location in political space (measured in terms the $x$-coordinate) and the distance from the origin. Both variograms have similar shapes, although the semi-variance for the political location is substantially higher than the semi-variance for the location's distance from the origin. This is to be expected, because the distance between two locations can be as high as 2 , whereas the maximum change in the distance from the origin is 1 .

\section{Decision-making Routines and Decision Maker Preferences}

Decision-making routines in the model are based on the theory of serial judgment proposed in Padgett (1980a). Serial judgment captures three common behavioral assumptions about group decision making. First, decision makers satisfice. A limited number of alternatives are considered by the group and the first acceptable alternative is adopted. Second, search is local. The set of alternatives under consideration in each period consist of one-bit changes to $\mathbf{x}$. Third, collective decisions in each period are stochastic. Alternatives are evaluated according to a random agenda and, as a result, groups facing the same set of alternatives at different times may reach different collective decisions.

Specifically, decision making in the organization occurs over a series of periods, or meetings. Prior to each meeting, the organization implements a status quo strategy $\mathbf{x}_{0}$. In the meeting, the organization considers a series of local alternatives $\mathbf{x}_{i}$, where $i \in\{1, \ldots, N\}$ indexes which decision is flipped from $\mathbf{x}_{0}$. Alternatives are considered sequentially in a random order. For each alternative under consideration, decision makers present at the meeting truthfully declare whether they prefer it to the status quo. Once all decision makers present agree that an alternative is (weakly) preferred to the status quo, it is adopted and the meeting adjourns. If no alternative receives unanimous support, then the status quo is maintained until the next period.

If decision making is dictatorial, then $z_{0}$ is always the sole participant at the meeting. If decision making is by committee, then the decision is left to $z_{1}, z_{2}$, and $z_{3}$, each of whom attends meetings with probability $p \in$ $(0,1]$. If no decision makers show up to a meeting, then $\mathbf{x}_{0}$ is retained. Of note, decision making by committee and mappings from strategies to quality with uncertainty capture the three characteristics of organized anarchies: unclear technology, problematic preferences, and fluid participation. Thus, comparisons of the relative performance of committees and dictators searching the performance landscape offer an opportunity to identify when garbage cans are adaptively rational organizational design.

Decision makers have bliss points in the unit disk that correspond to their most preferred strategies. $z_{0}$ 's bliss point $\pi_{0}$ lies at the origin. The others' bliss points $\pi_{1}, \pi_{2}$, and $\pi_{3}$ are distance $d$ from the origin and 
equally spaced from each other. Low values of $d$ indicate that the bliss points for $z_{1}, z_{2}$, and $z_{3}$ are closer together and, as a result, that the extent of conflict in the organization is low. Higher values of $d$ indicate that organization faces more substantial conflict. Let $\delta_{j}(\mathbf{x})$ indicate the Euclidean distance from the bliss point of decision maker $z_{j}$ to the location of strategy $\mathbf{x}$ in the unit disk where $j \in\{0,1,2,3\}$ indexes decision makers.

The four decision makers evaluate strategies $\mathbf{x}$ according to a utility function $f_{j}(\mathbf{x})$. Utility is linearly increasing in quality but decreasing quadratically with the political distance between a strategy and a decision maker's bliss point. Quadratic-loss spatial utility means that big deviations between the bliss point of an individual and the location of a strategy carry relatively more weight than smaller deviations, a behavioral assumption common in studies of political bargaining (see, e.g., Bendor and Meirowitz, 2004 Enelow and Hinich, 1984, Poole, 2001). Quadratic-loss utility also introduces risk aversion into the decision maker's utility function, because lotteries over more distant and more proximate outcomes are less preferred to known outcomes at the average of the two extremes.

$$
f_{j}(\mathbf{x})=v(\mathbf{x})-\delta_{j}(\mathbf{x})^{2}
$$

Following the adjournment of the meeting, the adopted strategy becomes the status quo for the next period, at which point the interaction begins anew.

I return to the example of the strategy 101001 to demonstrate the described decision-making routine. Let $\mathbf{x}_{0}$ indicate the status quo, 101001 , and $\mathbf{x}_{1}$ through $\mathbf{x}_{6}$ indicate the six one-bit transformations. Assume $d=\frac{1}{2}$ and $\pi_{1}, \pi_{2}$ and $\pi_{3}$ are located at $90^{\circ}, 210^{\circ}$, and $330^{\circ}$ around the origin respectively.

Table 1 lists $v(\mathbf{x}), g(\mathbf{x}), f_{0}, f_{1}, f_{2}$, and $f_{3}$. Under dictatorial decision making, the alternatives that are more desirable than $\mathbf{x}_{0}$ are $\mathbf{x}_{2}, \mathbf{x}_{4}$, and $\mathbf{x}_{5} . \mathbf{x}_{5}$ is both more ideologically proximate to $z_{0}$ 's bliss point and is higher quality. $\mathbf{x}_{2}$ and $\mathbf{x}_{4}$ are less preferable politically, but the improvement in quality more than makes up for the political cost. When decisions are made by committee, the outcome depends on who attends and the agenda. If just $z_{2}$ attends, then either $\mathbf{x}_{4}$ or $\mathbf{x}_{5}$ could be adopted. If just $z_{3}$ attends, then either $\mathbf{x}_{2}$ or $\mathbf{x}_{5}$ could be adopted. As a result, if $z_{2}$ and $z_{3}$ both attend, $\mathbf{x}_{5}$ is the only acceptable alternative. In contrast if $z_{1}$ and $z_{3}$ attend, $\mathbf{x}_{0}$ is retained, because $\mathbf{x}_{4}$, which is the only acceptable alternative for $z_{1}$, makes $z_{3}$ worse off than the status quo.

Finally, I explore how random incremental changes to strategies impact changes to the utility for the executive $f_{0}$. Figure 9 plots the distribution of changes to executive utility given incremental random search for $N=12$ and $K=0$ (on the left) or $K=5$ (on the right). Both are symmetric and centered at 0 . When $K=0$, however, the distribution is slightly more concentrated around 0. As a result, as displayed 
in Figure 10, the current strategy is slightly less informative about the utility from subsequent strategies following random search when $K=5$ compared to when $K=0$. However, on the whole, the variograms appear quite similar.

\section{Model Parameters, Extensions, and Robustness Checks}

A desirable feature of the model's setup is its ability to integrate alternative behavioral assumptions. It can straightforwardly accommodate changes to the number of choices $(N)$, the extent of interactions between them $(K)$, the extent of internal conflict $(d)$, or the number of decision makers $(j)$. In addition, the setup permits changes to the functional mapping between strategies and quality $(v(\mathbf{x}))$, political location $(g(\mathbf{x}))$, or utility $\left(f_{j}(\mathbf{x})\right)$. The primary analyses presented in this paper rely on defaults that are widespread in management theory and political economics. This explains, for example, why utility is linearly-increasing in $v(\mathbf{x})$ and quadratically-decreasing in $\delta_{j}(\mathbf{x})$. When in doubt, the assumptions in the paper reflect standard modeling practices in the relevant discipline.

Other assumptions are made for analytical convenience or to capture the range of interesting parameter combinations. The number of choices $N$ is assumed to be 12 in the simulations in order to balance the desire to have a sufficiently large set of potential strategies with the need for computational tractability (and the simplicity of having $N$ divisible by 3 ). $K$ is set to 0 or 5 to capture quality landscapes that are uncoupled and partially-coupled, respectively. The extent of political conflict similarly ranges from $d=\frac{1}{8}$ (minimal) to $d=\frac{1}{4}$ (moderate) to $d=\frac{1}{2}$ (high). Of note, all of the code used to produce the simulations is available in the supplementary materials and the code for the simulations is designed to make it easy for readers to experiment with different parameter combinations.

However, there are some more consequential assumptions that I also relax in order to evaluate the robustness of presented results. For example, in supplementary analyses, I report results from simulations where the number of decision makers in the committee range from 2 to 4 , where utility is linearly-decreasing $\delta_{j}(\mathbf{x})$ or cubically-decreasing in $\delta_{j}(\mathbf{x})$, where committees reach decisions by majority rule instead of by consensus, where a quorum of two is required in order for an alternative to be adopted, and where only the local alternatives that are most-favored by at least one decision maker present at the meeting are placed on the agenda. Finally, I also experiment with alternative mappings from strategies to the location in political space. In particular, I evaluate models that assume that the mapping from strategies to political location is non-invertible. In these models, strategies map to random locations in the unit disk. Different parameter combinations integrating these alternative assumptions are also easily implemented using the shared code. 


\section{Results}

I present results from 4000 simulated landscapes that the organization searches for 100 periods. All landscapes have 12 choices $(N=12)$. I consider technical landscapes with no interactions between choices $(K=0)$ and in which choices interact with five others $(K=5)$. When decisions are made by committee, political conflict is minimal $(d=1 / 8)$, moderate $(d=1 / 4)$, or high $(d=1 / 2)$ and decision makers attend meetings with $p=2 / 3$. When each new landscape is initialized, bliss points $\pi_{1}, \pi_{2}$, and $\pi_{3}$ are randomly rotated around the origin.

Because I am especially interested in comparisons between dictatorial and committee-based decision making, I present results in terms of the deviation of the average performance for committees relative to dictators for each combination of parameters. Furthermore, I show the difference in average utility from the perspective of the executive across the simulations, as well as the differences in average quality and differences in the average political distance from the origin. If the performance for a committee exceeds the performance for a dictator, it indicates that by delegating to a group with preferences that diverge from the executive's, the executive does better than when delegating to an ally. By evaluating outcomes from the executive's perspective, I can evaluate the conditions under which the ally principle fails to hold and garbage cans are indeed adaptively rational.

\section{Pure Political Conflict}

I first present results from simulations in which there is no variability in the quality of strategies. These results are consistent with Bendor and Shotts (2012) and demonstrate how the problems of political gridlock and chaotic outcomes make committee-based decisions suboptimal for a rational executive with a single-peaked utility function.

Figure 11a reports results when participation is rigid (i.e., $p=1$ ). In this case, delegation to the committee causes gridlock, not chaos. As predicted, in the medium and long-term, delegating to an ally outperforms delegating to a committee. Further, the relative performance of the dictatorship is increasing in the extent of political conflict. Of note, in the short-term, the moderate conflict condition performs best, followed by the minimal and high conflict conditions, followed by the dictator. The reason for this is because the divergence in preferences amongst the decision makers creates a higher threshold that alternatives must clear in order to be adopted. As such, for status quo strategies exterior to the Pareto region, adopted alternatives will tend to be closer to the origin when decisions are made by committee than when $z_{0}$ is in control. This feature of political decision making as a solution to satisficing individual decision makers is often overlooked, although a similar mechanism is at play in Cohen (1984). 
Figure 11b illustrates how performance changes when participation is fluid $\left(p=\frac{2}{3}\right)$. The fluid attendance at meetings means that the short-term benefit from political conflict is weakened. However, the long-term cost associated with delegating to the committee is also weakened, because strategies interior to the Pareto region are no longer retained in perpetuity. Yet, as in the case with rigid participation, medium and longterm performance under dictatorship dominates decision making by committee, and the cost of delegating to the committee is increasing in the extent of conflict.

Of note, in neither of these cases is decision making by committee consistent with the characteristics of a garbage can. In Figure 11a, preferences are problematic, but technology is not uncertain and participation is not fluid. In Figure 11b fluid preferences are added, but the landscape faced by the executive remains smooth and single-peaked.

\section{Introducing Common-interest Quality Uncertainty}

Next, I introduce uncertainty in quality via the NK landscape to the prior setup. Now, committee-based decision making is indeed consistent with organized anarchy, because technology is uncertain, preferences are problematic, and participation is fluid. The first case examines performance when $K=0$. Here, strategic choices make independent contributions to quality. In a traditional NK model, this makes for an easilysearched landscape, because greedy search eventually discovers the quality-maximizing strategy. In the model presented here, however, the introduction of political conflict introduces ruggedness in the executive's utility function $f_{0}$.

Imagine, for example, that $K=0$ and decisions equal to 1 have quality values of $1\left(v\left(x_{i}=1\right)=1\right)$ and decisions equal to 0 have quality values of $0\left(v\left(x_{i}=0\right)=0\right)$. The strategy that maximizes $f_{0}$ is $\mathbf{x}^{*}=11111111111$, because $f_{0}\left(\mathbf{x}^{*}\right)=v\left(\mathbf{x}^{*}\right)-\delta_{f}\left(\mathbf{x}^{*}\right)^{2}=1-0=1$. Assume the organization faces a status quo $\mathbf{x}_{0}=000100010001$ and, for the purposes of simplicity, that the $R$ component of the colorspace transformation is defined by choices 1 through $4, G$ is defined by choices 5 through 8 , and $B$ is defined by choices 9 through 12. (In the actual implementation of the model the mapping from choices to components would be randomly permuted.) Thus, $f_{0}=\frac{1}{4}$, because $\mathbf{x}_{0}$ maps to the origin and $v\left(\mathbf{x}_{0}\right)=\sum_{i} v\left(x_{i}\right) / 12=\frac{1}{4}$. Changing an decision from 0 to 1 will increase the quality value of the strategy by $\frac{1}{12}$ and changing an decision from 1 to 0 will decrease the quality value by $\frac{1}{12}$. If the organization selects an alternative that replaces a 1 with a 0 , then saturation will increase from 0 to 1 and, as a result, the new strategy will have a political outcome that is distance 1 from the origin. Thus, this alternative will be worse for the executive according to both the common-interest and politically-contested criteria. If instead the organization adopts an alternative that replaces a 0 with a 1 , the quality value would increase. But, the new outcome would fall 
at least $\frac{2}{5}$ away from the origin in political space $2^{2}$ Thus, the utility for $z_{0}$ from the alternative would be less than the utility from the status quo. This example thus shows how the interdependence between the NK landscape and the dimensions of political space leads the organization to retain $\mathbf{x}_{0}$ even though it is not the global maximum.

However, as is illustrated in Figure 12, minimal conflict is sufficient to overcome this ruggedness. Figure 12a reports the difference between average $f_{0}$ across the three levels of political conflict with average $f_{0}$ under dictatorship. Although committee-based decision making dominates dictatorship in the short term and long term, minimal-conflict committees $(d=1 / 8)$ dominate moderate-conflict committees $(d=1 / 4)$ which dominate high-conflict committee $(d=1 / 2)$. Figure 12b and Figure 12c represent the difference in the average values of the two criteria in $f_{0}$ : quality $v$ and political distance from the executive's bliss point $\delta_{0}$. For $d=1 / 8$, committee decision making dominates dictatorship in terms of quality for all 100 periods and also dominates in terms of political distance from $\pi_{0}$ in the short and long term from the perspective of the executive. This pattern captures the two ways that committee-based decision making improves upon dictatorial decision making. In the short term, the more stringent selection processes leads to better alternatives being adopted. In the long term, the stochastic search driven by chaotic political conflict permits desirable exploration.

For moderate conflict, the short vs. medium vs. long-term trade-offs are more substantial. From the $5^{\text {th }}$ through the $20^{\text {th }}$ period, dictatorial decision making produces higher utility for the executive. Further, in the long-term, there is a trade-off between quality and political distance from the origin. Moderate conflict promotes the discovery of higher quality strategies, but at the cost of strategies with political outcomes that are more distant from the executive's bliss point. For the high conflict case, in contrast, no such trade-off exists. Although in the very short term, the extreme disagreement over desirable outcomes leads to effective exploitation, committee decision making is quickly dominated by dictatorship according to both criteria.

Minimal political conflict no longer dominates moderate conflict, however, when the landscape that produces the quality criterion is itself rugged. Figure 13 replicates Figure 12 for $K=5$. Although the pattern for minimal conflict is barely changed, moderate conflict now dominates minimal conflict in the short and long term. The chaos generated by increased political conflict is functional when the mapping from strategies to quality is more complex. Until the $3^{\text {rd }}$ period, moderate conflict is preferable to minimal conflict due to the higher selection threshold. Then, from the $25^{\text {th }}$ period onward, it provides a better balance of search and stability. As in the $K=0$ case, the major benefit of committee-based chaotic search arises from improved quality. However, for $K=5$, the moderate conflict committee also discovers strategies that

\footnotetext{
${ }^{2}$ Saturation equals one minus the ratio of the minimum color value and the average. Therefore, the smallest change in the ideological space would result from changing $x_{3}, x_{7}$, or $x_{1}$ to a 1 . The new saturation value would be $1-\frac{3}{5}=\frac{2}{5}$.
} 
are better aligned politically with the executive's preferences than the ally $z_{0}$ would. The high conflict case continues to be dominated by dictatorship. Although higher-quality strategies are eventually discovered, the committee never adopts strategies that are both superior in quality and better-aligned politically with the executive's bliss point.

\section{Model Extensions}

Next, I examine the extent to which the results of the most recent set of simulations are robust to changes in modeling assumptions. I alter the decision making routines for the committee by requiring that a quorum of two is present for an alternative to be adopted and by changing the voting rule from unanimity rule to majority rule. I also alter the number of voters to examine the robustness of the model to smaller committees and larger ones. Next, I change the agenda-setting process so that only the most-favored alternatives are considered. I also alter the risk preferences of decision makers with respect to the political space, examining both linear loss functions and cubic loss functions. Finally, I examine whether the results in the model change when the mapping from strategies to locations in the political space is non-invertible.

All of the analyses begin with the following assumptions: $N=12, K=5, d \in\{1 / 8,1 / 4,1 / 2\}$, and $p=2 / 3$. For each condition, I report the following: Does the moderate-conflict condition outperform dictatorship in the short-term and, if so, until what period? Does the moderate-conflict condition outperform dictatorship in the long-term and, if so, beginning in what period? At $t=100$, does the moderate-conflict condition outperform the minimal- and high-conflict conditions, indicating that outcomes are non-monotonic with respect to the extent of conflict. I present the results from each scenario in Figure 14 .

First, I evaluate how the results change when committee decision making has a quorum requirement. This increases the threshold for adopting an alternative, because now a majority of decision makers must support a strategic change in order for it to be adopted, whether or not they attend the meeting where the change is being considered. Further, meetings without a quorum retain the status quo, adding inertia to the search process. The latter restriction imposed by the quorum requirement eliminates the short-term benefit of committee decision making. Although the moderate-conflict committee does outperform the dictator in the long-term, the former restriction considerably reduces the performance gap. In the $100^{\text {th }}$ period, utility for the executive after delegating to the moderate-conflict committee exceeds the utility if the executive delegated to $z_{0}$ by less than 0.01 . Additionally, in this case, the high-conflict committee actually outperforms the moderate- and minimal-conflict committees. The chaotic outcomes promoted by more conflict offset the restrictions on exploration created by the quorum requirement.

Next, I remove the quorum requirement and replace the unanimity voting rule with a majority voting 
rule. Specifically, I assume that an alternative must receive at least 50 percent support from the decision makers in attendance at a meeting. This has the opposite effect of the quorum requirement on the threshold for adopting a new alternative. If two decision members attend a meeting, an alternative can be adopted with support of just one decision maker. If three attend, then just two decision makers must support the alternative. In this case, the lower threshold for adoption of local alternatives eliminates the shortterm benefit of committees. In the long-term, however the performance of moderate-conflict committees is very similar to the performance of moderate-conflict committees that make decisions by unanimity rule. In addition, under majority voting, the performance of the moderate-conflict committee exceeds both the minimal- and high-conflict committees.

I next return to unanimity rule and explore how the results change if the committee consists of two or four decision makers. With two committee members, the more extreme conflict between decision makers and the higher likelihood of no decision makers attending a meeting removes the short-term benefits of committee decision making. In the long-term, however, the performance of moderate-conflict committees is similar to the three decision maker committee in terms of performance relative to the dictator and relative to the minimaland high-conflict committees. Expanding the committee to four decision makers, in contrast, has almost no effect on the performance of the minimal- and moderate-conflict committees. There remains a short-term and long-term benefit and the long-term performance is nearly identical. Expanding the committee beyond four, too, returns substantively similar results.

Another potential extension is changing the manner in which alternatives are added to the agenda. I explore whether restricting the agenda to most favored local alternatives changes the balance between exploration and exploitation. In theory, by restricting the potential alternatives being considered, this should make the committees more inert, as alternatives that make all attendees slightly better off will not be considered. This is indeed what I observe. The short-term benefit associated with committee-based decision making is eliminated and the long-term benefit is nearly zero. Although the moderate-conflict committee does outperform the dictatorship after period 67 , it is only by the slimmest of margins.

Next, I examine how sensitive results in the model are to the assumption that decision makers have quadratic-loss preferences. First, I examine the case where decision makers have linear spatial loss functions. In this case, the short-term benefits from committees are reduced and it takes considerably longer for the moderate-conflict committee to outperform the dictatorship. Further, the performance of committees is no longer non-monotonic with respect to the level of conflict. The minimal-conflict committee outperforms the modest- and high-conflict committees. This occurs because the linear spatial loss function makes the executive more sensitive to small deviations in outcomes away from their bliss point. As such, delegating to committees with better aligned bliss points is more valuable under linear loss than quadratic loss. The cubic 
loss function, in contrast, is more similar to the quadratic loss case, with one key difference. In the cubic case, the short-term benefit is both shorter-lived and relatively larger (as compared with the performance benefit in the $100^{\text {th }}$ period) than in the quadratic loss case.

Finally, I explore how the results change when the mapping from strategies to locations in political space is non-invertible. Specifically, in this scenario, every strategy maps to a random location in the unit disk. Small changes to strategies thus lead to movements in the political space that are as large, on average, as larger changes to strategies. The primary effect of moving from partially-invertible to noninvertible mappings from strategies to the political space is that incremental changes to strategies are more likely to have a non-local impact on outcomes in the latter case than in the former case. As a result, the benefits associated with conflict-based chaos are reduced. Thus, although the moderate-conflict committee continues to outperform the dictator in the short- and long-term, the minimal-conflict committee consistently outperforms the moderate-conflict committee.

On the whole, these extensions provide some insight into which of the simulation results are contingent on modeling assumptions and which hold more generally. In all cases, for example, some political conflict is desirable for the executive in order to overcome the problem of competency traps. However, when the politics-induced chaos is reduced due to a quorum requirement or a restricted agenda, the benefits to the executive in the long-term shrink considerably and in the short-term to go away entirely.

Moving from unanimity to majority rule or restricting committee membership to just two decision makers eliminates the short-term benefit of garbage cans. In both cases, the threshold for adopting a new strategy when the existing strategy is undesirable for the executive is too low. Linear spatial loss functions and non-invertible mappings from strategies to the political space also lead the results of the model to be monotonically-decreasing in the extent of conflict, although for different reasons. Finally, extending the number of committee members beyond three or increasing the risk aversion of decision makers does not appear to have a noticeable impact on the model's key results.

\section{Discussion and Conclusion}

It is hard to say something new and important about a model that is turning 50 years old, especially one that has motivated as much admiration, debate, and acrimony as the Garbage Can Model. Rather than saying something new, then, this paper says something old that has since been overlooked, perhaps even forgotten. The possibility that chaotic conflict could be a solution to the problem of search on uncertain landscapes was immediately recognized by management scholars intrigued by the Garbage Can Model. It is difficult to overstate just how radical these ideas were when placed in the context of prior research on the 
rational design of decision making institutions. The conclusion that an executive is better off delegating to an agent with aligned preferences than an agent with misaligned preferences is perhaps the most powerful theorem in organizational design. Yet, as emphasized in Pondy (1992), many great, durable, and important organizations are well-characterized as garbage cans, including legislatures, universities, social movements, and virtual communities.

This study develops a theoretical framework that supports a functional theory of chaotic organizational design. By integrating classic models from organizational theory and political science, it also provides a platform for understanding the interplay between political conflict and organizational search on rugged landscapes. The paper concludes by describing some conditions under which garbage can decision making is sensible organizational design. When the quality landscape is rugged and internal goal conflict is not too severe, executives looking for high quality strategies that are also aligned with political goals are better off delegating to garbage cans than to allies in the short term and in the long term. Further, performance is nonmonotonic in the extent of conflict when the ruggedness in the landscape that defines quality is sufficiently high. More conflict does not always lead to worse performance.

The paper also proposes a modeling framework that links between the rugged technical landscape and the ideological space in which conflict takes place. I introduce the colorspace transformation as a way to model the structure of internal political conflict that is both easily integrated with the NK model and consistent with existing research in political economics on spatial bargaining. The colorspace transformation permits different strategies to map to different trade-offs related to contested organizational goals. Political conflict, then, occurs in parallel with the search for high quality strategies.

The model leaves some questions open as well. The validity colorspace representation of individual perception of political conflict is well-worth exploring further, particularly given the ubiquity of the use of colorspaces to describe the dimensions of ("big-P") political conflict and the frequent use of colors as political labels for sets of contested issues. For example, one feature of the colorspace transformation that is not explored here is its ability to seamlessly incorporate common decision-making biases. Color theorists noticed that the perception of color is dependent on characteristics of the external environment and the other colors presented nearby long before decision theorists noticed the same about individual choice Albers, 2013). An additional promising extension of this research would also be to study this search task in a lab environment. One possibility would be to expand the well-known "alien game," in which participants are asked to design geometric artistic products for alien life forms, to incorporate committee-based search and divergent individual tastes about color (Billinger et al. 2014). In addition to testing the behavioral validity of the model's conclusions, the results of a lab experiment would also allow the simulation's assumptions to be calibrated in a manner consistent with observed individual and group behavior. 
The results of the model also have important implications for existing empirical research on intragroup conflict. In particular, the results point to the importance of dynamic considerations in the design of experimental studies on conflict in organizations. Collective performance in conflict-ridden groups may differ greatly depending on whether the group faces a straightforward, discrete task or a complex task requiring search over an extended period of time. At the same time, insights from research on conflict in teams can also be integrated more fully into this theoretical framework in the future. A consideration not addressed here, for example, is the emotional cost of conflict to individual well-being and the potential for (productive) political conflict to become (unproductive) relationship or process conflict (De Dreu and Weingart, 2003. Jehn, 1995). Just because chaotic conflict produces good outcomes in the long term for the organization in theory does not mean that individuals will perceive it that way, especially after a series of contentious and frustrating meetings.

Further, the model presented here brackets a series of questions traditionally of interest to organizational economics that could be explored in further research. For example, the potential for endogenous attendance at meetings is not explored (Feddersen, 2004, Levinthal, 2012). Neither are questions related to individual beliefs about untried strategies (Callander, 2011; Ganz, 2020). Like other research in the garbage can family, this paper strikes a particular balance with regards to assumptions related to individual agency. Some of these behavioral assumptions are undoubtedly important - e.g., the extent to which decision makers are able to sample non-local strategies matters a great deal - and others are less so - e.g., the particular colorspace conversion has a very limited impact on model outcomes.

Given that the original formulation of the Garbage Can Model so overtly denies agency to decision makers, the durable impact of Cohen et al. (1972) on theories of organizational design is perhaps surprising. Padgett (2013) speculates that the original statement of the Garbage Can Model embodied the desire of "Cohen, March, and Olsen...simultaneously to be scientific engineers and pioneering botanists." My paper, like others before it that bring actor agency into the garbage can framework, instead reflects the approach of a gardener. Prior work at the intersection of garbage can decision making and organizational design, however, starts with the assumption that garbage cans are unkempt. Thus, the role of the organizational designer, like that of a formal French gardener, is to bring orderly hierarchy to unruly chaos. This paper, in contrast, argues that the disorderly decisions in the Garbage Can Model are well-adapted to certain problems that organizations face. Rather than trying to constrain the chaos, a rational executive, like an English landscape gardener, should exploit it. 


\section{References}

Albers, Josef, Interaction of Color, 50th anniversary edition ; 4th edition ed., New Haven: Yale University Press, 2013.

Ansolabehere, Stephen, Jonathan Rodden, and James M Snyder, "Purple America," Journal of Economic Perspectives, May 2006, 20 (2), 97-118.

Austen-Smith, David and Jeffrey S. Banks, Positive Political Theory I: Collective Preference Michigan Studies in Political Analysis, Ann Arbor: University of Michigan Press, 1999.

Barnett, W.P. and Michael Woywode, "From Red Vienna to the Anschluss: Ideological Competition among Viennese Newspapers during the Rise of National Socialism," American Journal of Sociology, May 2004, 109 (6), 1452-1499.

Battaglini, Marco, "Multiple Referrals and Multidimensional Cheap Talk," Econometrica, July 2002, 70 (4), 1379-1401.

Behfar, Kristin J., Elizabeth A. Mannix, Randall S. Peterson, and William M. Trochim, "Conflict in Small Groups: The Meaning and Consequences of Process Conflict," Small Group Research, April 2011, 42 (2), 127-176.

Bendor, J., A. Glazer, and T. Hammond, "Theories of Delegation," Annual Review of Political Science, June 2001, 4 (1), 235-269.

Bendor, Jonathan and Adam Meirowitz, "Spatial models of delegation," American Political Science Review, 2004, 98 (2), 293-310.

- and Kenneth W. Shotts, "Chance, Preferences, and Predictions in Garbage Can Theory," in "The Garbage Can Model of Organizational Choice: Looking Forward at Forty," Vol. 36 of Research in the Sociology of Organizations, Emerald Group Publishing Limited, January 2012, pp. 99-137.

Billinger, Stephan, Nils Stieglitz, and Terry R. Schumacher, "Search on Rugged Landscapes: An Experimental Study," Organization Science, February 2014, 25 (1), 93-108.

Callander, Steven, "A theory of policy expertise," Quarterly Journal of Political Science, July 2008, 3 (2), $123-140$.

_ , "Searching and Learning by Trial and Error," American Economic Review, 2011, 101, 2277-2308. 
Cohen, Michael D., "Conflict and Complexity: Goal Diversity and Organizational Search Effectiveness," The American Political Science Review, 1984, 78 (2), 435-451.

_, James G. March, and Johan P. Olsen, "A Garbage Can Model of Organizational Choice," Administrative Science Quarterly, 1972, pp. 1-25.

_ , _, and _ , "A Garbage Can Model At Forty: A Solution that Still Attracts Problems," in Alessandro Lomi and J. Richard Harrison, eds., Research in the Sociology of Organizations, Vol. 36, Emerald Group Publishing Limited, January 2012, pp. 19-30.

Crawford, Vincent P. and Joel Sobel, "Strategic Information Transmission," Econometrica: Journal of the Econometric Society, 1982, 50 (6), 1431-1451.

Csaszar, Felipe A. and J. P. Eggers, "Organizational Decision Making: An Information Aggregation View," Management Science, 2013, 59 (10), 2257-2277.

Dreu, Carsten K. W. De and Evert Van de Vliert, eds, Using conflict in organizations, London: SAGE, 1997. OCLC: 833011914.

- and Laurie R. Weingart, "Task versus relationship conflict, team performance, and team member satisfaction: A meta-analysis.," Journal of Applied Psychology, 2003, 88 (4), 741-749.

Eisenhardt, Kathleen M. and L. J. Bourgeois, "Politics of Strategic Decision Making in High-Velocity Environments: Toward a Midrange Theory," Academy of Management Journal, 1988, 31 (4), 737-770.

- and Mark J. Zbaracki, "Strategic decision making," Strategic Management Journal, 1992, 13 (S2), $17-37$.

_, Jean L. Kahwajy, and L. J. Bourgeois, "How management teams can have a good fight," Harvard Business Review, 1997, 75, 77-86.

Elkington, John, "Towards the Sustainable Corporation: Win-Win-Win Business Strategies for Sustainable Development," California Management Review, January 1994, 36 (2), 90-100.

Enelow, James M. and Melvin J. Hinich, The spatial theory of voting: an introduction, Cambridge [Cambridgeshire] ; New York: Cambridge University Press, 1984.

Ethiraj, Sendil K. and Daniel Levinthal, "Hoping for A to Z While Rewarding Only A: Complex Organizations and Multiple Goals," Organization Science, February 2009, 20 (1), 4-21. 
Feddersen, Timothy J, "Rational Choice Theory and the Paradox of Not Voting," Journal of Economic Perspectives, February 2004, 18 (1), 99-112.

Fligstein, Neil, The Transformation of Corporate Control, Cambridge, Mass: Harvard University Press, 1990.

Ganz, Scott C., "Ignorant Decision Making and Educated Inertia: Some Political Pathologies of Organizational Learning," Organization Science, January 2018, 29 (1), 39-57.

_ , "Hyperopic Search: Organizations Learning About Managers Learning About Strategies," Organization Science, April 2020, p. orsc.2019.1330.

Gavetti, Giovanni, Daniel Levinthal, and William Ocasio, "Perspective-Neo-Carnegie: The Carnegie School's Past, Present, and Reconstructing for the Future," Organization Science, 2007, 18 (3), 523-536.

_, Henrich R. Greve, Daniel A. Levinthal, and William Ocasio, "The Behavioral Theory of the Firm: Assessment and Prospects," Academy of Managament Annals, 2012, 6 (1), 1-40.

Gibbons, Robert, Niko Matouschek, and John Roberts, "Decisions in Organizations," in Robert Gibbons and John Roberts, eds., The Handbook of Organizational Economics, Princeton: Princeton University Press, 2012, pp. 373-431.

Gilligan, Thomas W. and Keith Krehbiel, "Asymmetric Information and Legislative Rules with a Heterogeneous," American Journal of Political Science, May 1989, 33 (2), 459.

Giuli, Alberta Di and Leonard Kostovetsky, "Are red or blue companies more likely to go green? Politics and corporate social responsibility," Journal of Financial Economics, January 2014, 111 (1), 158180.

Gonzalez, Rafael C. and Richard E. Woods, Digital image processing, New York, NY: Pearson, 2018.

Gruenfeld, Deborah H., "Status, ideology, and integrative complexity on the U.S. Supreme Court: Rethinking the politics of political decision making.," Journal of Personality and Social Psychology, 1995, 68 (1), 5-20.

Jehn, Karen A., "A Multimethod Examination of the Benefits and Detriments of Intragroup Conflict," Administrative Science Quarterly, June 1995, 40 (2), 256.

_ , "Affective and Cognitive Conflict in Work Groups: Increasing Performance Through Value-based Intragroup Conflict," in "Using Conflict in Organizations," London: SAGE, 1997, pp. 9-22. 
Kaplan, Sarah, "Framing Contests: Strategy Making Under Uncertainty," Organization Science, October 2008, $19(5), 729-752$.

Kellogg, Katherine C., "Operating Room: Relational Spaces and Microinstitutional Change in Surgery," American Journal of Sociology, November 2009, 115 (3), 657-711.

Knudsen, Thorbjorn and Daniel A. Levinthal, "Two Faces of Search: Alternative Generation and Alternative Evaluation," Organization Science, 2007, 18 (1), 39-54.

Levine, Sheen S., Evan P. Apfelbaum, Mark Bernard, Valerie L. Bartelt, Edward J. Zajac, and David Stark, "Ethnic diversity deflates price bubbles," Proceedings of the National Academy of Sciences, December 2014, 111 (52), 18524-18529.

Levinthal, Daniel A., "Adaptation on Rugged Landscapes," Management Science, 1997, 43 (7), 934-950.

_ , "From the Ivy Tower to the C-suite: Garbage Can Processes and Corporate Strategic Decision Making," in Alessandro Lomi and J. Richard Harrison, eds., The Garbage Can Model of Organizational Choice: Looking Forward at Forty, number 36. In 'Research in the Sociology of Organizations.', Emerald Group Publishing Limited, January 2012, pp. 349-362.

Lomi, Alessandro and J. Richard Harrison, "Introduction," in Alessandro Lomi and J. Richard Harrison, eds., The Garbage Can Model of Organizational Choice: Looking Forward at Forty, 1. ed ed. number 36.2012. In 'Research in the sociology of organizations.', Bingley: Emerald, 2012. OCLC: 820692939.

March, James G., "Exploration and Exploitation in Organizational Learning," Organization Science, January 1991, $2(1), 71-87$.

_ and Johan P. Olsen, Ambiguity and choice in organizations, Bergen: Universitetsforlaget, 1976.

Marengo, Luigi, "Organizational politics and complexity: Coase vs. Arrow, March, and Simon," Industrial and Corporate Change, February 2020, 29 (1), 95-104.

McKelvey, Richard D, "Intransitivities in multidimensional voting models and some implications for agenda control," Journal of Economic Theory, June 1976, 12 (3), 472-482.

Mithani, Murad A. and Jonathan P. O'Brien, "So What Exactly Is a "Coalition" Within an Organization? A Review and Organizing Framework," Journal of Management, January 2021, 47 (1), 171-206.

Moch, Michael K. and Louis R. Pondy, "The Structure of Chaos: Organized Anarchy as a Response to Ambiguity," Administrative Science Quarterly, 1977, 22 (2), 351-362. 
O'Reilly, Charles A. and Michael L. Tushman, "Organizational Ambidexterity: Past, Present, and Future," Academy of Management Perspectives, 2013, 27 (4), 324-338.

Padgett, John F., "Bounded Rationality in Budgetary Research," American Political Science Review, June $1980,74(2), 354-372$.

_ , "Managing Garbage Can Hierarchies," Administrative Science Quarterly, December 1980, 25 (4), 583.

_ , "Alessandro Lomi and J. Richard Harrison, eds.: Research in the Sociology of Organizations, vol. 36:

The Garbage Can Model of Organizational Choice: Looking Forward at Forty," Administrative Science Quarterly, September 2013, 58 (3), 472-482.

Pfeffer, Jeffrey, Power in Organizations, Cambridge: Ballinger Pub. Co., 1981.

Phillips, Katherine W., Katie A. Liljenquist, and Margaret A. Neale, "Is the Pain Worth the Gain? The Advantages and Liabilities of Agreeing With Socially Distinct Newcomers," Personality and Social Psychology Bulletin, March 2009, 35 (3), 336-350.

Pondy, Louis R., "Reflections on organizational conflict," Journal of Organizational Behavior, May 1992, $13(3), 257-261$.

Poole, Keith T., "The Geometry of Multidimensional Quadratic Utility in Models of Parliamentary Roll Call Voting," Political Analysis, 2001, 9 (3), 211-226. Publisher: [Oxford University Press, Society for Political Methodology].

Puranam, Phanish, Nils Stieglitz, Magda Osman, and Madan M. Pillutla, "Modelling Bounded Rationality in Organizations: Progress and Prospects," The Academy of Management Annals, January 2015, 9 (1), 337-392.

Reagans, Ray and Ezra W. Zuckerman, "Networks, Diversity, and Productivity: The Social Capital of Corporate R\&D Teams," Organization Science, 2001, 12 (4), 502-517.

Rivkin, Jan W. and Nicolaj Siggelkow, "Balancing Search and Stability: Interdependencies Among Elements of Organizational Design," Management Science, March 2003, 49 (3), 290-311.

Shepsle, Kenneth A. and Barry R. Weingast, "Structure Induced Equilibrium and Legislative Choice," Public Choice, 1981, 37, 503-519.

Siggelkow, Nicolaj and Daniel A. Levinthal, "Temporarily Divide to Conquer: Centralized, Decentralized, and Reintegrated Organizational Approaches to Exploration and Adaptation," Organization Science, December 2003, 14 (6), 650-669. 
Zbaracki, Mark J. and Mark Bergen, "When Truces Collapse: A Longitudinal Study of Price-adjustment Routines," Organization Science, 2010, 21 (5), 955-972. 
Table 1: Local Search from $z=101001$

\begin{tabular}{ccccccc}
\hline $\mathbf{x}$ & $v(\mathbf{x})$ & $g(\mathbf{x})$ & $f_{0}$ & $f_{1}$ & $f_{2}$ & $f_{3}$ \\
\hline $\mathbf{x}_{0}: 101001$ & $\frac{1}{2}$ & $(0.2,0.35)$ & 0.34 & 0.44 & -0.26 & 0.09 \\
\hline $\mathbf{x}_{1}: 001001$ & $\frac{1}{3}$ & $(-0.87,0.5)$ & -0.67 & -0.42 & -0.42 & -1.92 \\
\hline $\mathbf{x}_{2}: 111001$ & $\frac{2}{3}$ & $(0.43,0.25)$ & 0.42 & 0.42 & -0.33 & 0.42 \\
\hline $\mathbf{x}_{3}: 100001$ & $\frac{1}{3}$ & $(0.87,-0.5)$ & -0.67 & -1.42 & -1.42 & 0.08 \\
\hline $\mathbf{x}_{4}: 101101$ & $\frac{2}{3}$ & $(0,0.5)$ & 0.42 & 0.67 & -0.08 & -0.08 \\
\hline $\mathbf{x}_{5}: 101011$ & $\frac{2}{3}$ & $(-0.07,-0.12)$ & 0.65 & 0.27 & 0.52 & 0.40 \\
\hline $\mathbf{x}_{6}: 101000$ & $\frac{1}{3}$ & $(0.5,0.87)$ & -0.67 & -0.05 & -1.78 & -0.92 \\
\hline
\end{tabular}

Note: The table includes all six local alternative to $\mathbf{x}_{0}$ and decision maker evaluations of each alternative. 
Figure 1: Gridlock, Bias, and Instability in Spatial Bargaining

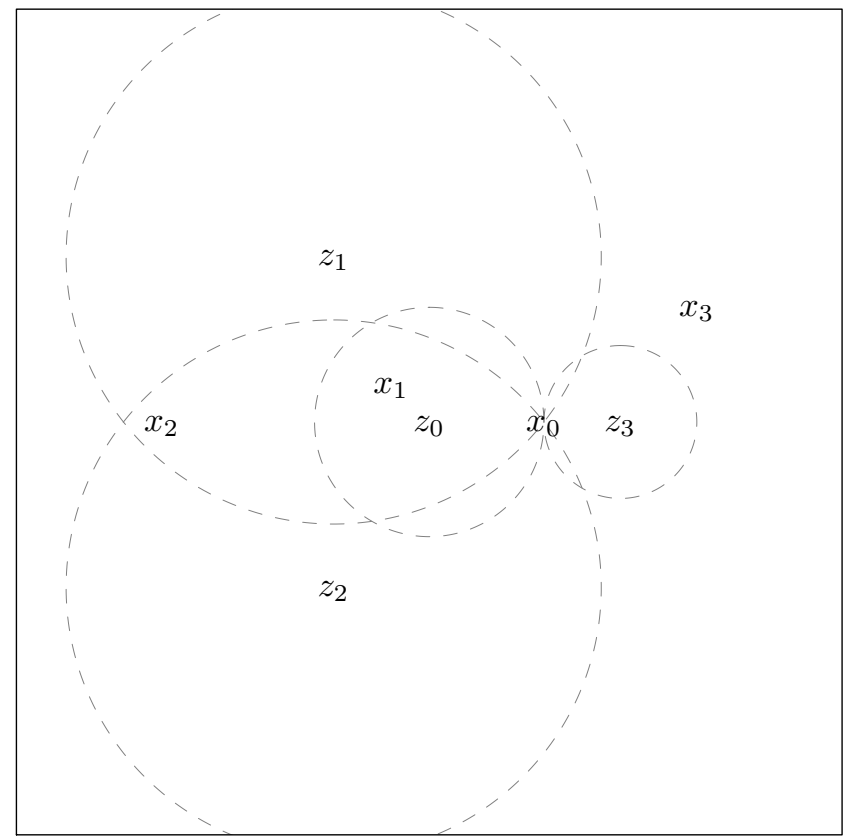

Note: The figure captures the dynamics of spatial bargaining among three decision makers with bliss points at $z_{0}, z_{1}, z_{2}$, and $z_{3}$ choosing among strategies $x_{1}, x_{2}$, and $x_{3}$. 
Figure 2: Calculating Quality using an NK landscape

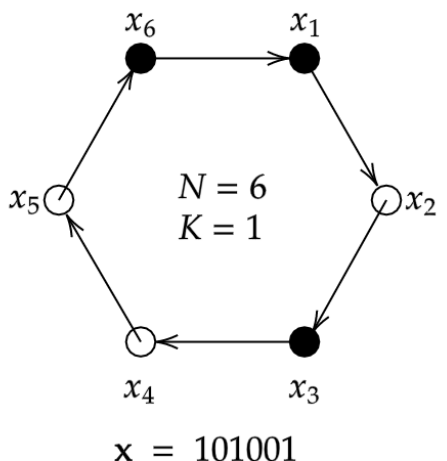

$v\left(x_{i}\right)$ represents the quality contribution of each decision $x_{i}$ $v\left(x_{i}\right)$ depends on the binary decision associated with the $i^{\text {th }}$ choice and the decisions associated with the $K$ choices that follow. Quality contributions associated with each potential set of decisions are drawn randomly from the unit interval.

For this example, assume:

$$
\begin{aligned}
& v\left(x_{1} \mid x_{i}=0, x_{i+1}=0\right)=0 \\
& v\left(x_{i} \mid x_{i}=0, x_{i+1}=1\right)=\frac{3}{4} \\
& v\left(x_{i} \mid x_{i}=1, x_{i+1}=0\right)=\frac{1}{4} \\
& v\left(x_{i} \mid x_{i}=1, x_{i+1}=1\right)=1
\end{aligned}
$$

$v(\mathbf{x})=\frac{1}{N} \sum_{i \in 1 \ldots N} v\left(x_{i}\right)=$

$\frac{1}{6}\left(\frac{3}{4}+\frac{1}{4}+\frac{3}{4}+\frac{1}{4}+0+1\right)=\frac{1}{2}$

$x_{3}$ is switched from 1 to 0 , which changes the quality contibutions of $x_{2}$ and $x_{3}$. The overall quality of the strategy decreases from

$$
\begin{aligned}
& v(\mathbf{x})=\frac{1}{2} \text { to } v\left(\mathbf{x}^{\prime}\right)=\frac{1}{3} \text {. } \\
& \mathbf{x}^{\prime}=100001 \\
& v\left(\mathbf{x}^{\prime}\right)=\frac{1}{N} \sum_{i \in 1 \ldots N} v\left(x_{i}\right)= \\
& \frac{1}{6}\left(\frac{3}{4}+0+0+0+\frac{1}{4}+1\right)=\frac{1}{3}
\end{aligned}
$$

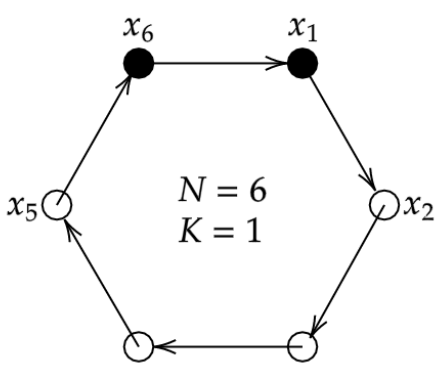

Note: The figure illustrates how the quality value is calculated given a set of six decisions in an NK model. 
Figure 3: Distribution of Change in Quality Given Random Incremental Search

(a) Change in Quality for $K=0$

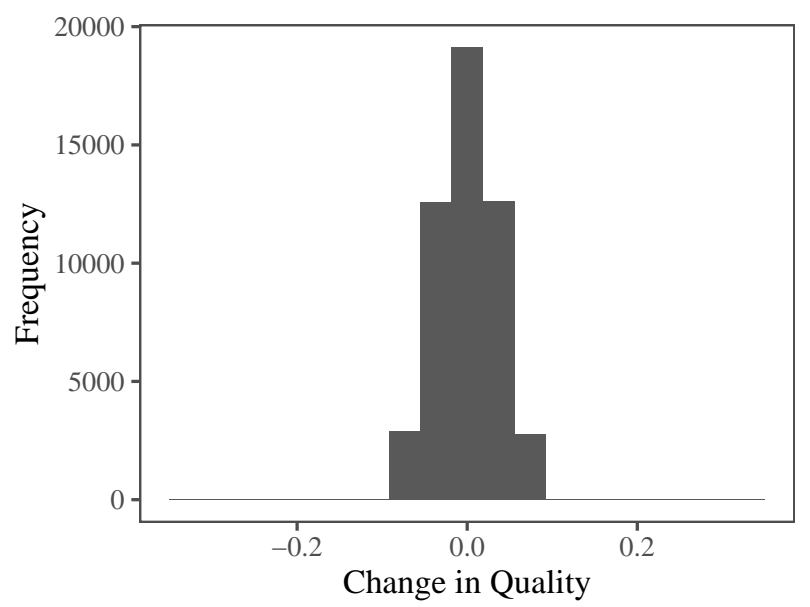

(b) Change in Quality for $K=5$

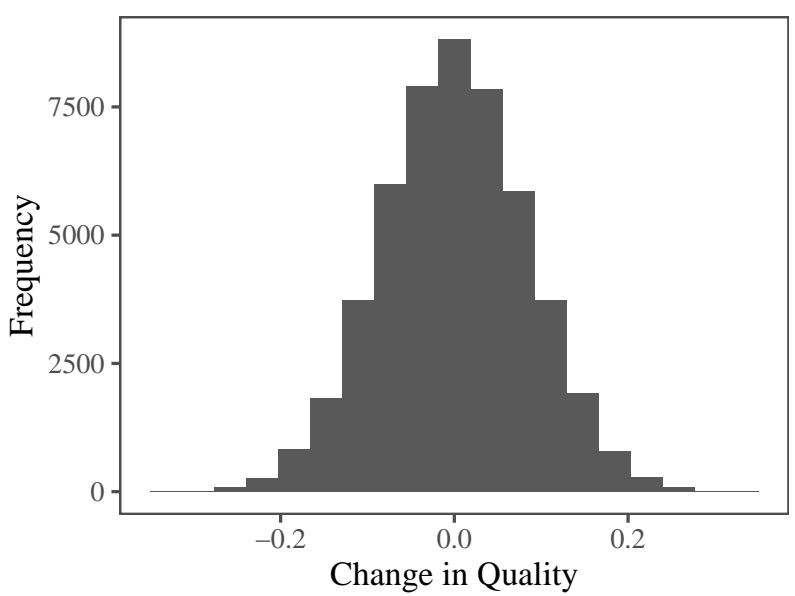

Note: The histograms display the distribution of changes to quality conditional on random incremental search for $N=12$ and $K=0$ (left) or $K=5$ (right).

Figure 4: Variogram for the NK landscape

(a) Variogram for $K=0$

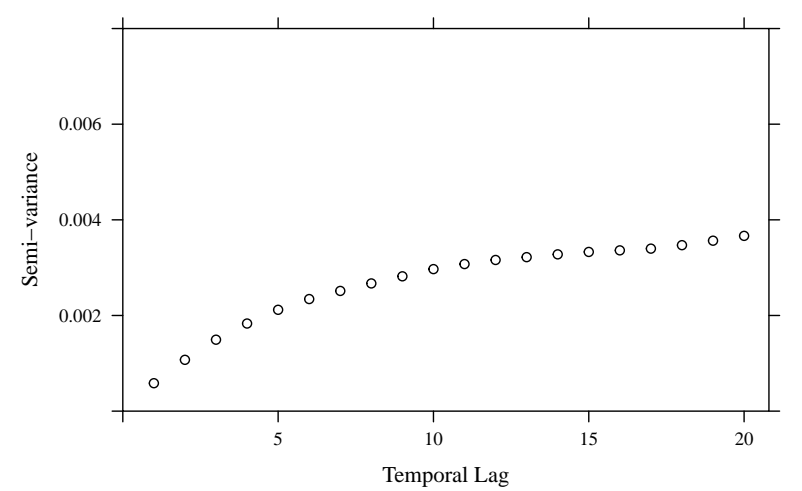

(b) Variogram for $K=5$

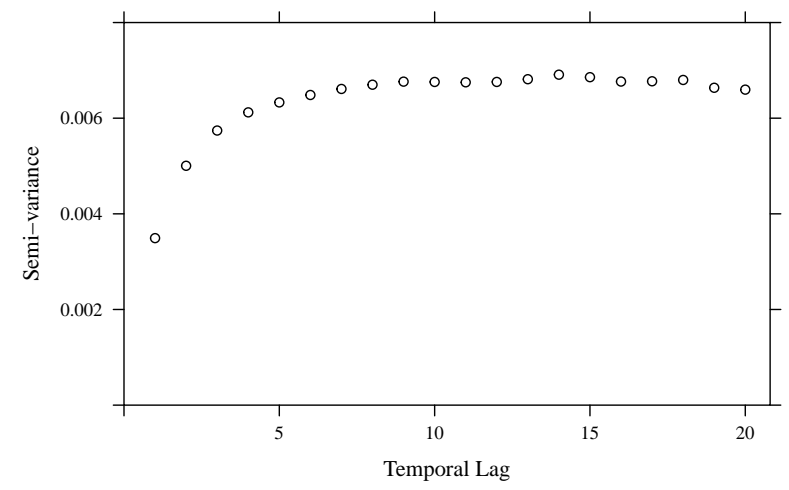

Note: The figure depicts variograms for an NK landscape where $N=12$ and $K=0$ (on the left) or $K=5$ (on the right). 
Figure 5: Mapping from $\mathbf{x}$ to the Political Space

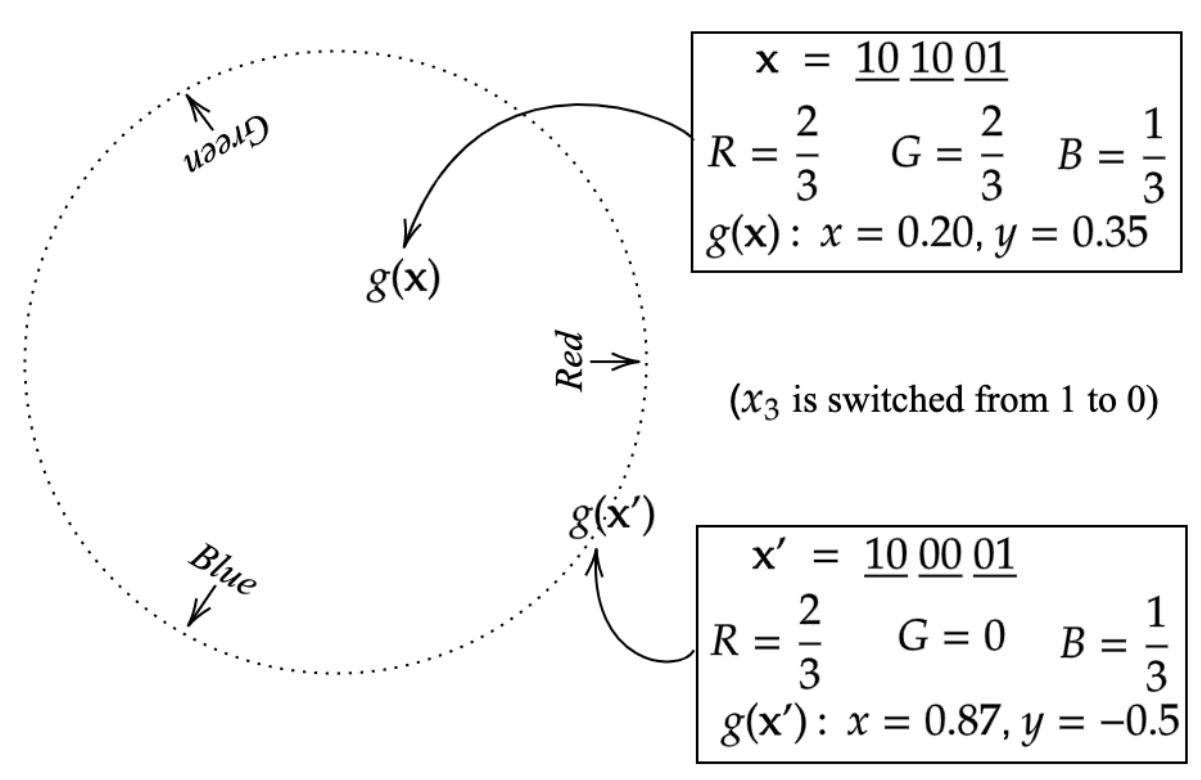

Note: The figure shows how the mapping from a strategy to a location in the unit disk is calculated and the change to location resulting from a one-bit change to the strategy. 
Figure 6: Euclidean Locations $g\left(\mathbf{x}^{\prime}\right)$ when $N=6$

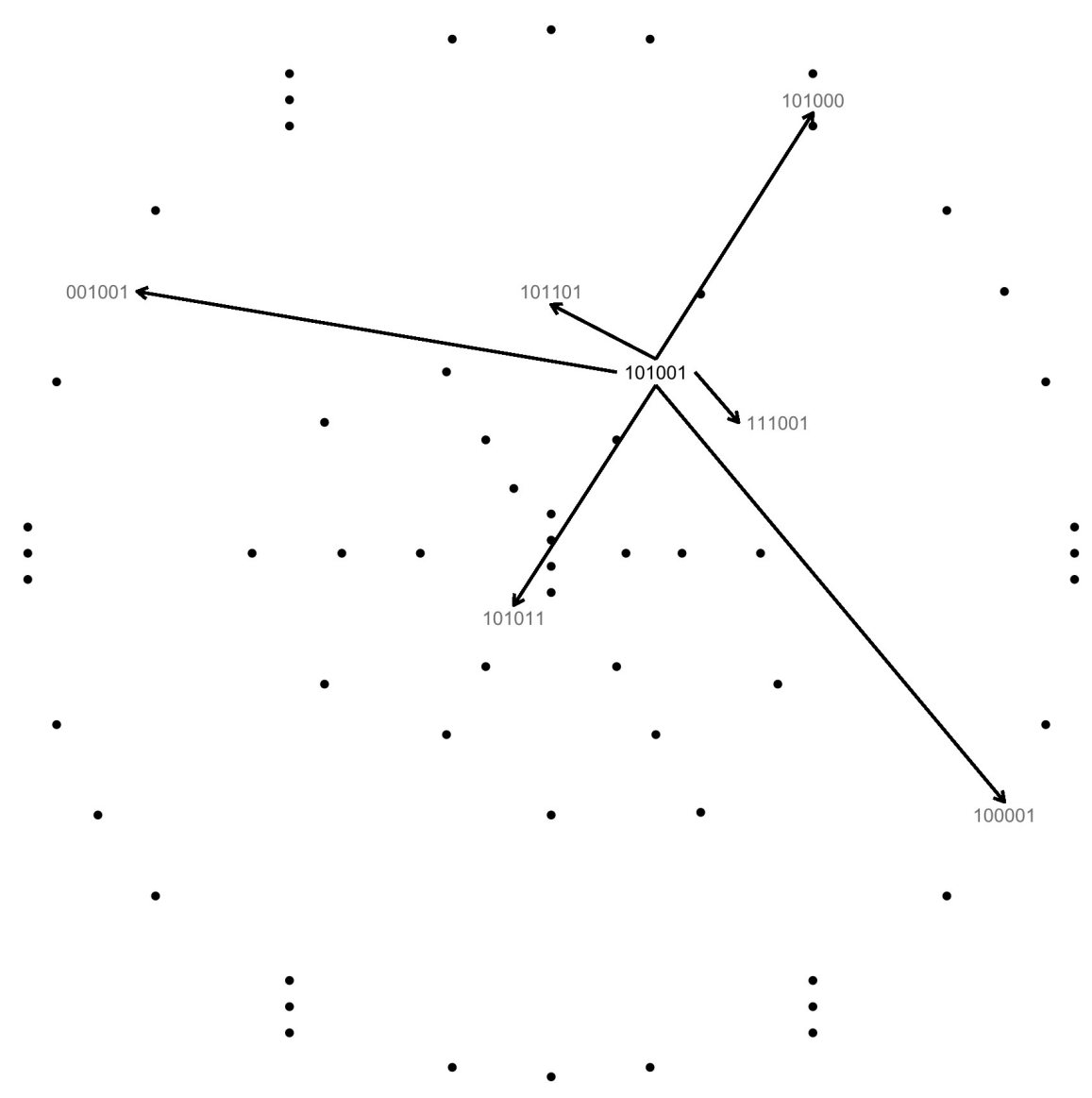

Note: The figure depicts the complete mapping from strategies to locations in the political space for $N=6$. Stacked dots indicate more than one $\mathbf{x}^{\prime}$ map to a location

Figure 7: Distribution of Change in Political Location Given Random Incremental Search

(a) Change in Location in Political Space

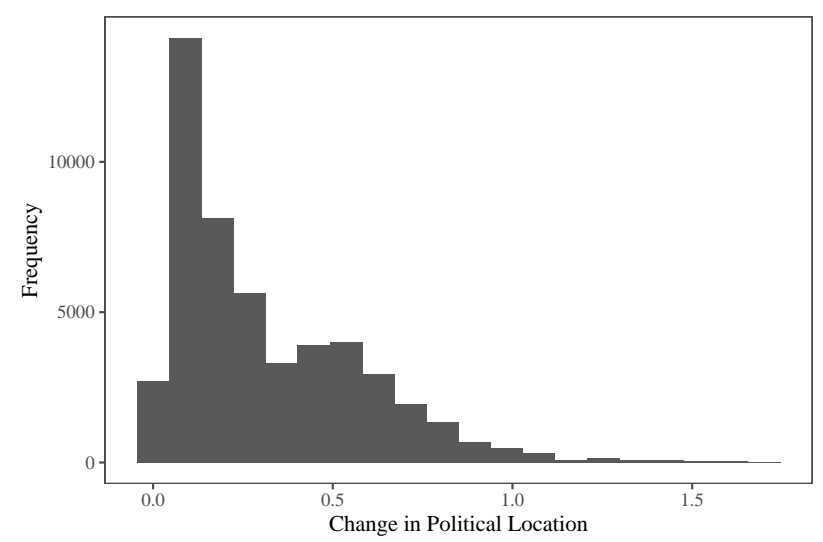

(b) Change in Distance from Origin

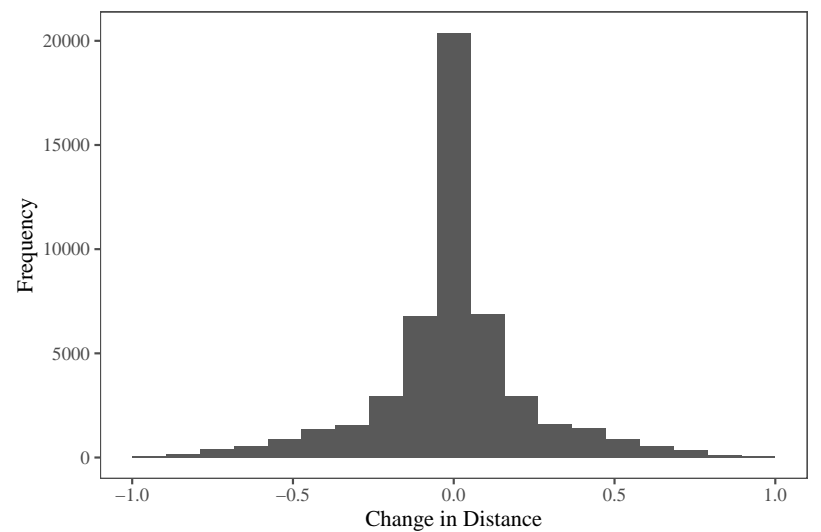

Note: The histograms display the distribution of changes to political location (on the left) and distance from the origin (on the right) conditional on random incremental search for $N=12$. 
Figure 8: Variogram for Political Location

(a) Variogram for $x$-coordinate Value

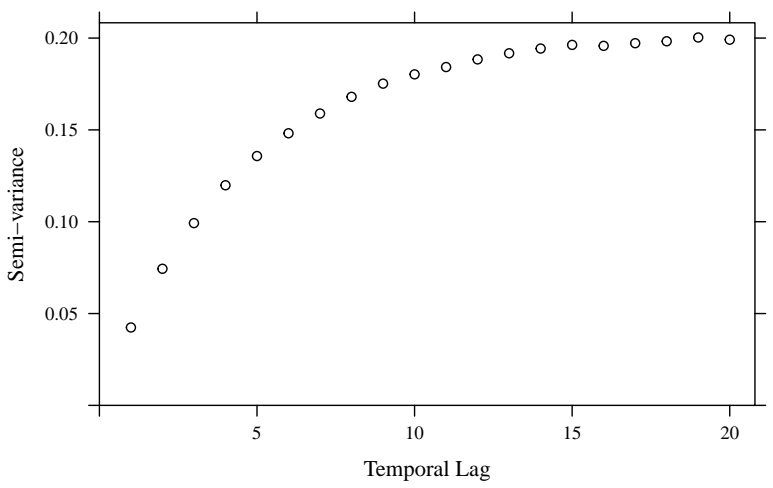

(b) Variogram for Distance from Origin

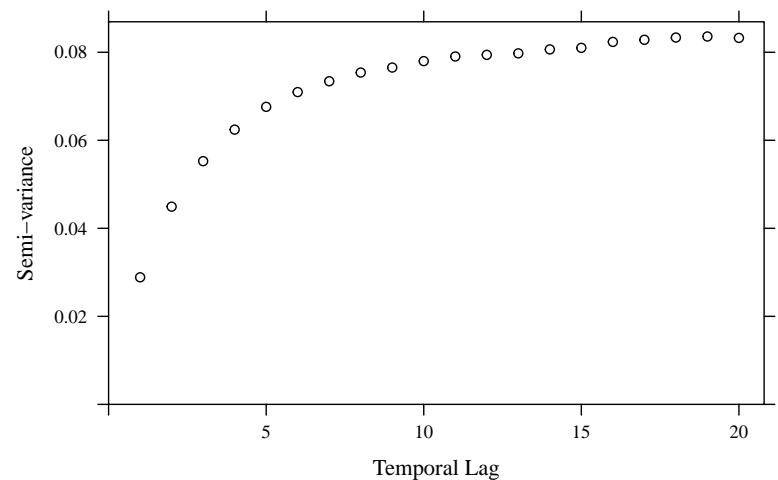

Note: The figure depicts variograms for the mapping from strategies to the $x$-coordinate in the political space (on the left) and distance from the origin (on the right).

Figure 9: Distribution of Change in Executive Utility $f_{0}$ Given Random Incremental Search

(a) $K=0$

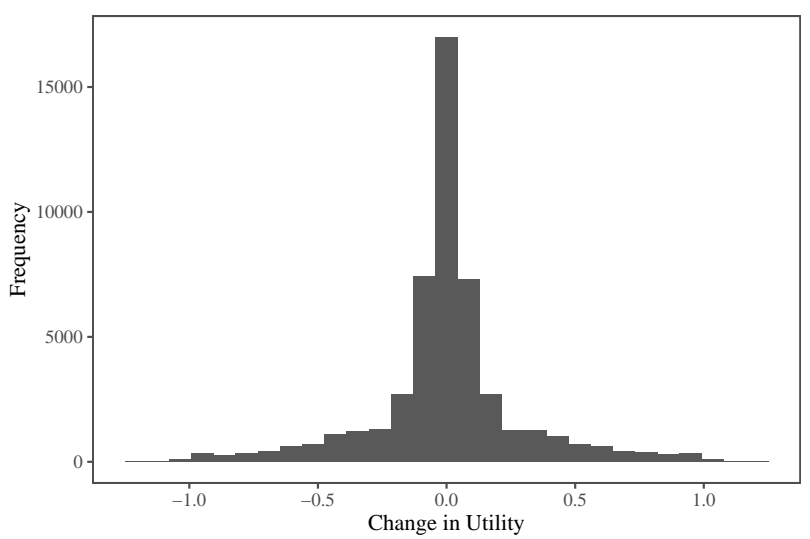

(b) $K=5$

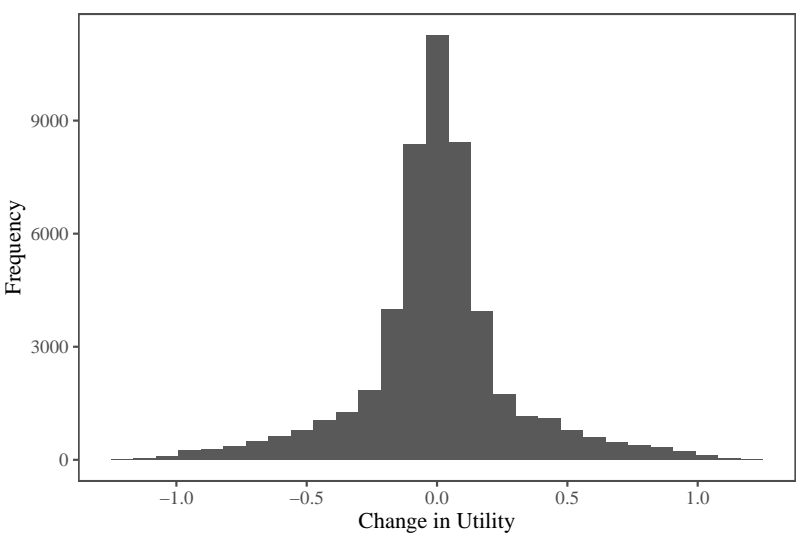

Note: The histograms display the distribution of changes to utility for the executive conditional on random incremental search for $N=12$ and $K=0$ (left) or $K=5$ (right). 
Figure 10: Variogram for Executive Utility $f_{0}$
(a) $K=0$
(b) $K=5$
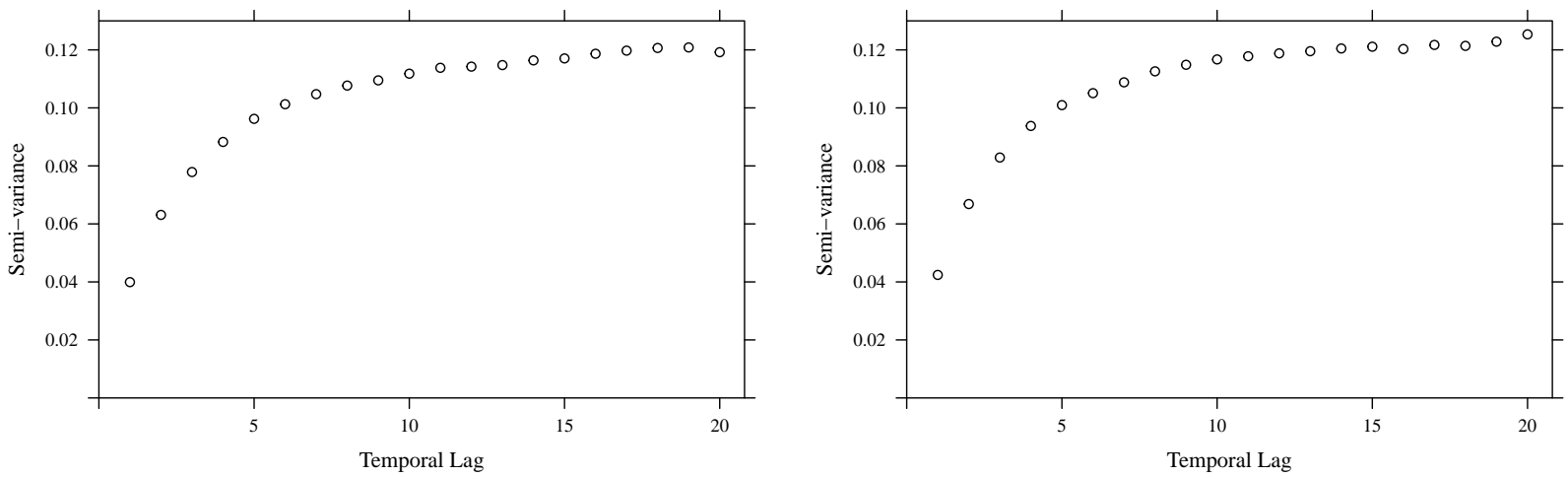

Note: The figure depicts variograms for the mapping from strategies to utility for the executive for $N=12$ and $K=0$ (on the left) and $N=12$ and $K=5$ (on the right).

Figure 11: Average Utility with Constant Quality

(a) Rigid Participation, $p=1$

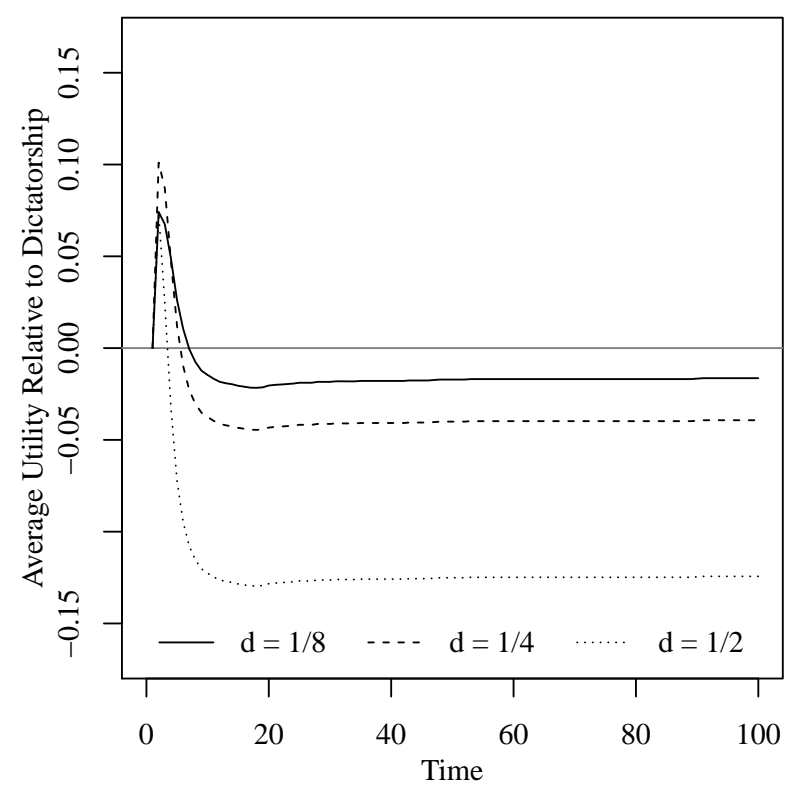

(b) Fluid Participation, $p=2 / 3$

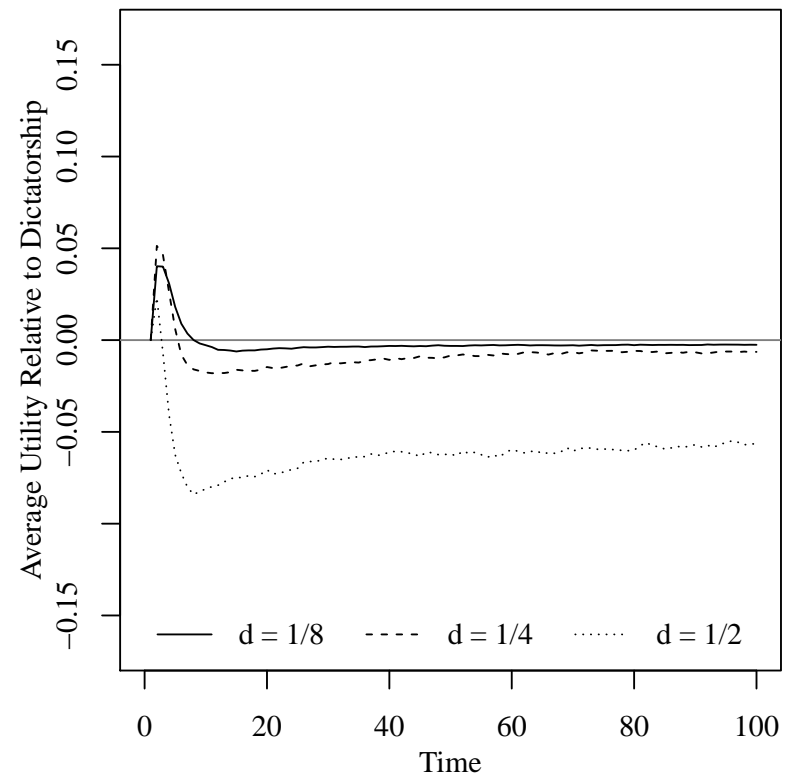

Note: The graphs compare the utility for the executive under dictatorship and committee-based decision making for committees with $d \in\{1 / 8,1 / 4,1 / 2\}$. The graph on the left shows results for committees with rigid participation and on the right shows results for committees with fluid participation. 
Figure 12: Utility, Quality, and Political Distance from Origin with Quality Uncertainty, $K=0$

(a) Average Utility, $E\left(f_{0}(\mathbf{x})\right)$

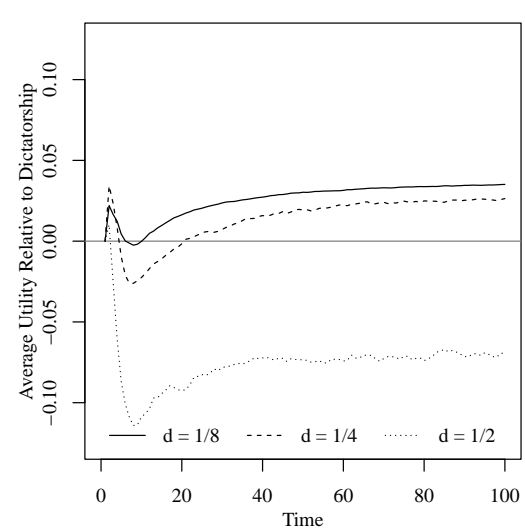

(b) Average Quality, $E(v(\mathbf{x}))$

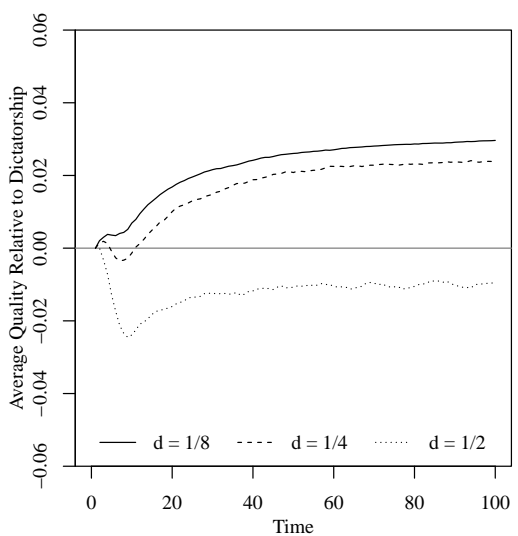

(c) Average Pol. Distance, $E\left(\delta_{0}(\mathbf{x})\right)$

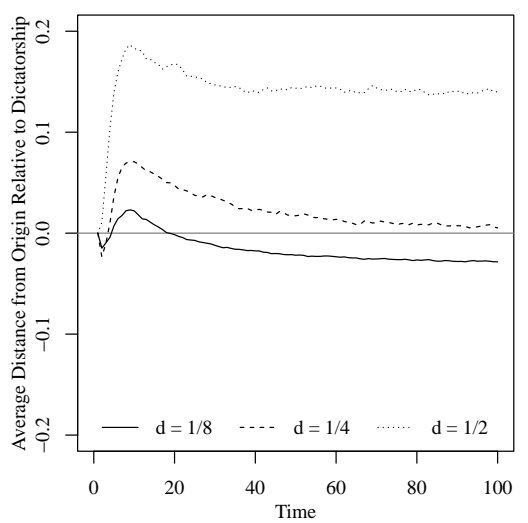

Note: The graphs show the the utility for the executive, common-interest quality, and distance from the origin for committees with $d \in\{1 / 8,1 / 4,1 / 2\}$. All results are presented in terms of their divergence from outcomes when decision are made dictatorially.

Figure 13: Utility, Quality, and Political Distance from Origin with Quality Uncertainty, $K=5$

(a) Average Utility, $E\left(f_{0}(\mathbf{x})\right)$

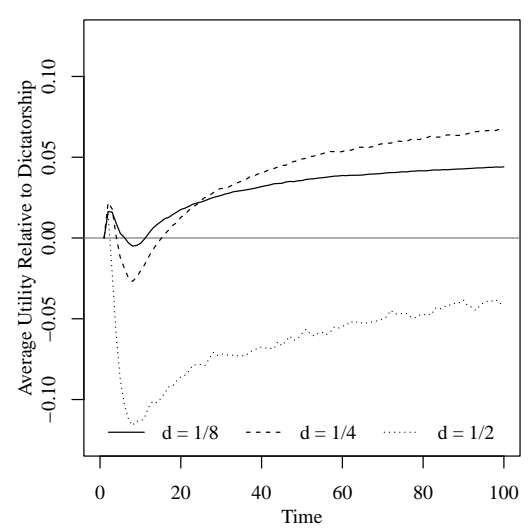

(b) Average Quality, $E(v(\mathbf{x}))$

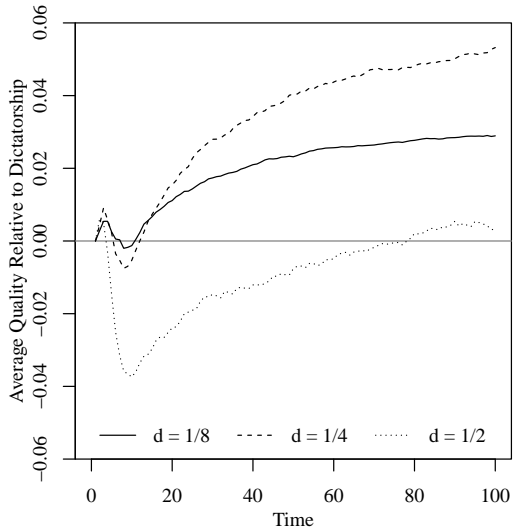

(c) Average Pol. Distance, $E\left(\delta_{0}(\mathbf{x})\right)$

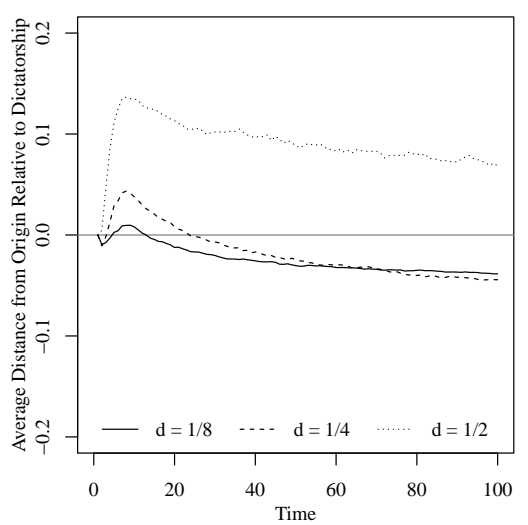

Note: The graphs show the the utility for the executive, common-interest quality, and distance from the origin for committees with $d \in\{1 / 8,1 / 4,1 / 2\}$. All results are presented in terms of their divergence from outcomes when decision are made dictatorially. 
Figure 14: Results under Alternative Assumptions

\begin{tabular}{|c|c|c|c|c|c|}
\hline $\begin{array}{l}\text { Does moderate- } \\
\text { conflict } \\
\text { committee } \\
\text { outperform } \\
\text { dictatorship in } \\
\text { short-term? }\end{array}$ & $\begin{array}{c}\text { If so, until } \\
\text { what period? }\end{array}$ & $\begin{array}{l}\text { Does moderate- } \\
\text { conflict } \\
\text { committee } \\
\text { outperform } \\
\text { dictatorship in } \\
\text { long-term? }\end{array}$ & $\begin{array}{c}\text { If so, } \\
\text { beginning } \\
\text { what period? }\end{array}$ & $\begin{array}{l}\text { If so, by how } \\
\text { much does } f_{0} \\
\text { with moderate- } \\
\text { conflict } \\
\text { committee } \\
\text { exceed } f_{0} \text { with } \\
\text { dictatorship at } \\
t=100\end{array}$ & $\begin{array}{l}\text { Is performance } \\
\text { non-monotonic } \\
\text { in the extent } \\
\text { of conflict at } \\
t=100 ?\end{array}$ \\
\hline \multicolumn{6}{|c|}{ Base Case: $N=12, K=5, d \in\{1 / 8,1 / 4,1 / 2\}, p=2 / 3$} \\
\hline Yes & 4 & Yes & 16 & 0.06 & Yes \\
\hline \multicolumn{6}{|c|}{ Quorum Requirement: Two decision makers must be present to adopt an alternative } \\
\hline No & & Yes & 26 & $<0.01$ & No \\
\hline \multicolumn{6}{|c|}{ Voting Rule: Decisions are made by majority rule } \\
\hline No & & Yes & 24 & 0.06 & Yes \\
\hline \multicolumn{6}{|c|}{ Committee Size: Two decision maker committee } \\
\hline No & & Yes & 22 & 0.06 & Yes \\
\hline \multicolumn{6}{|c|}{ Committee Size: Four decision maker committee } \\
\hline Yes & 5 & Yes & 18 & 0.06 & Yes \\
\hline \multicolumn{6}{|c|}{ Agenda-setting: Restricted to most-preferred local alternatives } \\
\hline No & & Yes & 67 & $<0.01$ & No \\
\hline \multicolumn{6}{|c|}{ Risk preferences: Linear spatial loss function } \\
\hline Yes & 2 & Yes & 50 & 0.03 & No \\
\hline \multicolumn{6}{|c|}{ Risk preferences: Cubic spatial loss function } \\
\hline Yes & 2 & Yes & 14 & 0.04 & Yes \\
\hline \multicolumn{6}{|c|}{ Mapping for Strategies to Political Location: Non-invertible function } \\
\hline Yes & 2 & Yes & 30 & 0.03 & No \\
\hline
\end{tabular}

